Research Article

\title{
Study on the Preparation and Fracture Behavior of Red Mud-Yellow Phosphorus Slag-Based Concrete
}

\author{
Xianhai Li $\mathbb{D}^{1},{ }^{1,2,3,4}$ Qin Zhang $\mathbb{D}^{2,3,4}$ Song Mao, ${ }^{2,3,4}$ Longjiang $L i,{ }^{1,2,3,4}$ and Jingbo Wang ${ }^{2,3,4}$ \\ ${ }^{1}$ College of Materials and Metallurgy, Guizhou University, Guiyang 550025, China \\ ${ }^{2}$ Mining College, Guizhou University, Guiyang 550025, China \\ ${ }^{3}$ National \& Local Joint Laboratory of Engineering for Effective Utilization of Regional Mineral Resources from Karst Areas, \\ Guiyang 550025, China \\ ${ }^{4}$ Guizhou Key Lab of Comprehensive Utilization of Non-metallic Mineral Resources, Guizhou University, Guiyang 550025, China
}

Correspondence should be addressed to Qin Zhang; zq6736@163.com

Received 22 February 2019; Revised 25 June 2019; Accepted 8 July 2019; Published 30 October 2019

Academic Editor: Akbar Heidarzadeh

Copyright (c) 2019 Xianhai Li et al. This is an open access article distributed under the Creative Commons Attribution License, which permits unrestricted use, distribution, and reproduction in any medium, provided the original work is properly cited.

Serious environmental pollution issues caused by the storage and exposure of large amounts of red mud (RM) and yellow phosphorus slag (YPS) have raised significant concerns. Red mud-yellow phosphorous slag-cement concrete (RM-YPS-CC) is prepared with $25 \%$ yellow phosphorus slag content (YPSC) and $10 \%$ red mud content (RMC) to replace a portion of the cement at the age of 28 days and was found in this study to satisfy the mechanical property requirements. More ettringite and portlandite were generated with the RM-YPS-CC than with the yellow phosphorous slag-cement concrete (YPS-CC). In addition, the cementitious materials were more interlaced, and there was more disorder in the crystals of the RM-YPS-CC, which formed a more complex spatial structure than the YPS-CC did. Without RM, the initial cracking strength on the surface of the concrete was 5-6 MPa, the maximum crack width was $3.96 \mathrm{~mm}$, and the crack number was 8 . However, the cracking strength was $26.5-27 \mathrm{MPa}$ with RMC5, the maximum crack width was $0.66 \mathrm{~mm}$ with RMC15, and the crack number was 3 with RMC15. Moreover, studies using the digital image correlation (DIC) method indicated that the displacement distribution and evolution of the first crack area changed quickly at $10 \mathrm{MPa}$ in either horizontal or vertical direction, and a similar trend was maintained from $10 \mathrm{MPa}$ to $27.1 \mathrm{MPa}$ for the YPS-CC. However, with a small distribution and evolution of horizontal or vertical displacement from $5 \mathrm{MPa}$ to $25 \mathrm{MPa}$, the evolution would change rapidly when reaching $30 \mathrm{MPa}$ for RM-YPS-CC. This study aims to provide new insights into the wide application of YPS and RM for saving energy and reducing emissions and to develop a new method to study the fracture behavior of concrete.

\section{Introduction}

Stockpiling and discharging of large amounts of industrial solid waste not only affects the environment but also restricts the development of enterprises. In China, many enterprises are facing a significant challenge to protect the environment from damage caused by industrial solid waste disposal. Yellow phosphorus slag (YPS) is a kind of industrial waste generated after water quenching, produced during the hot production process of yellow phosphorus; the output of yellow slag is $8-10$ tons of slag per 1 ton of industrially produced yellow phosphorus [1]. The YPS utilization ratio in
China is very low, with over 8 million tons of generated YPS waiting to be utilized every year [2,3]. Serious environmental issues caused by elemental $\mathrm{P}$ and $\mathrm{F}$ in YPS warrant further study to avoid resource waste and environmental pollution [4]. Red mud (RM) is an alkaline leaching waste generated during the Bayer process or the bauxite-calcination method, which produce up to twice as much RM as alumina [5, 6], approximately $0.3-1.0$ tons of RM is generated per 1 ton of aluminum produced in industries [7, 8]. There is an estimated 3 billion tons of accumulated RM globally, with the worldwide generation of RM exceeding 117 million tons per year in recent years $[8,9]$. The discharge 
of RM seriously impacts the environment and groundwater because of its high alkaline content $\left(\mathrm{Na}_{2} \mathrm{O}\right.$ 2.0-6.0\%) [10-12].

Cement is a vital cementitious material for any kind of construction, and it is widely used throughout the world [13]. However, the cement industry is one of the main emission sources of greenhouse gas (especially $\mathrm{CO}_{2}$ ), and excessive $\mathrm{CO}_{2}$ emission can result in global warming and ecological destruction [14]. Cement is expected to be replaced by solid industrial wastes with pozzolanic properties considering global sustainable development, depletion of the raw materials, and low carbon emissions [13, 15]. Application of mineral admixtures to concrete might improve the workability, durability, and mechanical properties of concrete [16-18]. Studies indicate that concrete containing mineral admixtures exhibits a low reaction degree during the early ages and achieves a lower early strength than plain cement concrete $[19,20]$. New kinds of mineral admixtures are gradually being used in concrete production because the traditional mineral admixtures are becoming increasingly scarce [2]. Recently, in the cement industry, there has been an increasing interest in partially or completely replacing cement with industrial solid wastes, such as fly ash [21, 22], yellow phosphorous slag [4, 23], red mud $[24,25]$, blast furnace slag $[26,27]$, and phosphogypsum $[28,29]$.

YPS is similar to but less reactive than blast furnace slag (BFS) and is mainly composed of $\mathrm{CaO}$ and $\mathrm{SiO}_{2}[30,31]$. Previous studies indicated that YPS can refine the late-age pore structure of hardened paste, reduce the chloride diffusion coefficient, enhance the compressive strength, and improve the durability of concrete $[2,32]$. In addition, the trace amount of fluoride and phosphorus in YPS can increase the activity of the clinker mineral during dissolution and can help improve the cement clinker strength [33]. RM is a good binder material in cement matrices because RM contains a considerable amount of amorphous aluminosilicate materials that can induce a pozzolanic reaction to cause gelation during the hydration process $[34,35]$. In addition, $\mathrm{RM}$ can be used to produce special iron-rich cement clinkers and pozzolanic pigment for colored concrete because of the abundance of hematite in RM $[36,37]$. Additionally, RM can be developed as an alkali-activated material for practical application to the construction industry. However, RM cannot exceed a certain amount in building materials; for example, the portion of RM generated in building materials in Guizhou, China, should be less than $75.44 \%$ by contribution analysis of nuclides to radiation [38, 39]. Several studies were conducted on the application of YPS and RM as building material additives. Qi et al. [4] conducted several studies on the pozzolanic effects of YPS powder in concrete. Chen et al. [1] found that YPS could fully or partly be substituted for Portland cement, and they evaluated the potential coagulation properties by conducting studies on the cemented backfilling performance of YPS. Research conducted by Liu and Poon [40] and Pan et al. [41] also suggested that RM can be used as a substitute for cement.

After an extensive review of the literature, we found that despite the existence of some studies in the field of partially replacing cement with RM or YPS, there were not any investigations into the synergistic effects of RM and YPS partially replacing cement. Inspired by the abovementioned studies, this paper discussed how YPS and RM can be applied to partially replace cement to prepare red mud-yellow phosphorus slag-cement concrete (RM-YPS-CC) by stimulating the activity of concrete to achieve solid waste utilization and pollution reduction. The effects of yellow phosphorus slag content (YPSC) and red mud content (RMC) on the mechanical properties of concretes were investigated by using a hydraulic pressure compression testing machine followed by X-ray diffraction (XRD), scanning electron microscopy (SEM), and energy dispersive spectrometry (EDS). The shape, size, and number of cracks on the surface of concrete and initial cracking strength were investigated under an applied load. The displacement distribution and evolution of the first crack area of yellow phosphorous slag-cement concrete (YPS-CC) and RM-YPSCC under different applied load levels were studied by the digital image correlation (DIC) method [42], which has become popular for displacement and deformation measurements in the field of experiment mechanics.

\section{Experimental Procedure}

2.1. Raw Materials. The YPS used in this study was obtained from a phosphorus plant in Guizhou, China. The RM (loss of ignition $=12.86 \%$ ) used was obtained from an alumina refinery in Guizhou, China, and it was found by XRD (X Pert Powder, PanakoX-ray Analysis Instruments, Netherlands) to contain mainly quartz, calcium oxide, hematite, alumina, and small amount of chlorite and garnet. A laser particle size analyzer (LS13320, Beckman Coulter, America) was used to obtain the particle size distributions of the RM and YPS, as shown in Figure 1. The particle size of the YPS was distributed in $-2.1+0.6 \mu \mathrm{m}$ and $-80+10 \mu \mathrm{m}$, and $D_{90}=53.97 \mu \mathrm{m}$ and $D_{10}=0.93 \mu \mathrm{m}$. The particle size of the RM was evenly distributed: $D_{90}=201.7 \mu \mathrm{m}$ and $D_{10}=2.828 \mu \mathrm{m}$. The specific gravities of the YPS and RM were 2.95 and 2.82, respectively. The cement was $42.5 \mathrm{R}$ common Portland cement produced by a cement plant in Guizhou, China, and the physical properties of the cement are shown in Table 1. The chemical composition of the cement, YPS, and RM was analyzed by $\mathrm{X}$-ray fluorescence (Axios $\mathrm{mA} \times 4 \mathrm{KW}$, Panalytical, Netherlands), and the results are shown in Table 2 . The water reducer (WR) was JC484-2006. Tap water from the laboratory was used for the tests, and the specific gravity of the tap water was approximately $1000 \mathrm{~kg} / \mathrm{m}^{3}$. The coarse aggregate (CA) was crushed carbonate stone, and the fine aggregate (FA) was the standard sand; both were manufactured according to the Chinese National Standard GB/T17671-1999, and the FA and CA size distributions are shown in Table 3.

\subsection{Mixture Proportion and Experimental Method}

2.2.1. Mixture Proportions and Preparation of the Concrete Specimens. The concrete mixtures were prepared for examination by mixing different proportions of cement, WR, CA, FA, YPS, and RM (Tables 4 and 5). The water/binder 


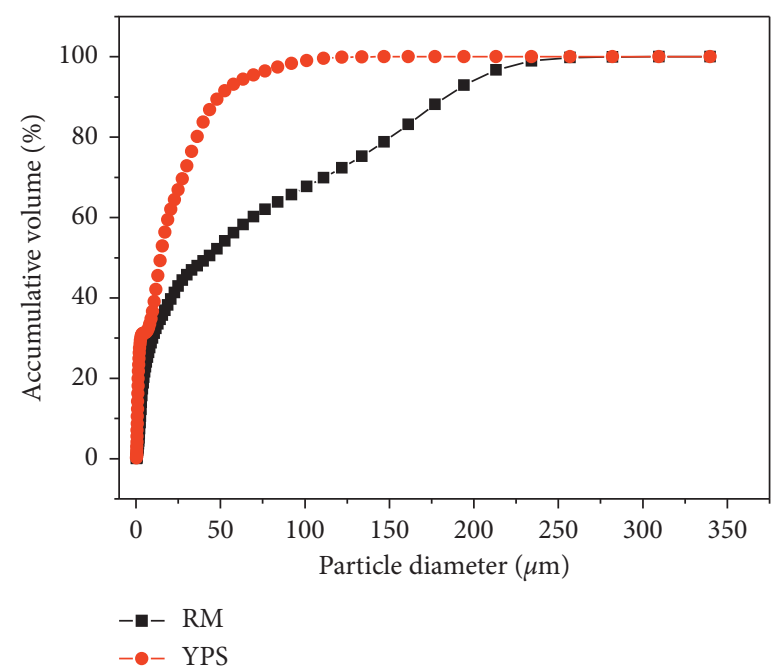

Figure 1: Particle size distribution of the RM and YPS.

TABle 1: Physical properties of cement.

\begin{tabular}{lccccc}
\hline \multicolumn{2}{c}{ Setting time $(\mathrm{min})$} & \multicolumn{2}{c}{$\begin{array}{c}\text { Compressive } \\
\text { strength }(\mathrm{MPa})\end{array}$} & Specific surface ${\operatorname{area~}\left(\mathrm{cm}^{2} \cdot \mathrm{g}^{-1}\right)}$ & Density $\left(\mathrm{g} \cdot\left(\mathrm{cm}^{3}\right)\right.$ \\
\hline Initial setting & Final setting & $3 \mathrm{~d}$ & $28 \mathrm{~d}$ & \\
\hline 108 & 125 & 29.1 & 55.1 & 3945 & 3.09 \\
\hline
\end{tabular}

TABLE 2: Chemical composition of cement, YPS, and RM.

\begin{tabular}{lccccccccc}
\hline \multirow{2}{*}{ Name } & \multicolumn{9}{c}{ Oxide composition (wt. \%) } \\
& $\mathrm{SiO}_{2}$ & $\mathrm{CaO}$ & $\mathrm{Al}_{2} \mathrm{O}_{3}$ & $\mathrm{TiO}_{2}$ & $\mathrm{Fe}_{2} \mathrm{O}_{3}$ & $\mathrm{MgO}$ & $\mathrm{K}_{2} \mathrm{O}$ & $\mathrm{Na}_{2} \mathrm{O}$ & $\mathrm{P}_{2} \mathrm{O}_{5}$ \\
\hline Cement & 20.08 & 60.65 & 4.61 & 0.55 & 3.36 & 1.98 & 0.54 & 0.85 \\
YPS & 37.22 & 44.77 & 5.42 & 0.26 & 0.45 & 2.61 & 1.43 & 0.33 \\
$\mathrm{RM}$ & 17.33 & 16.32 & 21.09 & 4.69 & 21.93 & 1.89 & 1.21 & 1.46 & 0.34 \\
\hline
\end{tabular}

TABLE 3: Aggregate size distribution of the FA and CA.

\begin{tabular}{lccccccc}
\hline \multirow{2}{*}{ Aggregate } & \multicolumn{5}{c}{ Aggregate diameter distribution (mm) } \\
& +8 & $-8+2$ & $-2+1.6$ & $-1.6+1.0$ & $-1.0+0.5$ & $-0.5+0.16$ & $-0.16+0.08$ \\
\hline FA (\%) & 0 & 0 & 6.9 & 27.3 & 34.3 & 19.4 \\
CA (\%) & 0 & 100 & 0 & 0 & 0 & 0 & 11.5 \\
\hline
\end{tabular}

TABLE 4: Mixture proportions of YPS-CC (by weight).

\begin{tabular}{|c|c|c|c|c|c|c|c|c|c|}
\hline \multirow{2}{*}{ No. } & \multirow{2}{*}{ YPS (\%) } & \multirow{2}{*}{ WR $(\%)$} & \multirow{2}{*}{ FA (\%) } & \multicolumn{6}{|c|}{$1 \mathrm{~m}^{3}$ concrete material composition $(\mathrm{g})$} \\
\hline & & & & Water & Cement & YPS & WR & FA & CA \\
\hline A & 20 & & & & 400 & 100 & & & \\
\hline B & 25 & & & & 375 & 125 & & & \\
\hline $\mathrm{C}$ & 30 & 0.5 & 33 & 250 & 350 & 150 & 2.5 & 635 & 800 \\
\hline $\mathrm{D}$ & 35 & & & & 325 & 175 & & & \\
\hline $\mathrm{E}$ & 40 & & & & 300 & 200 & & & \\
\hline
\end{tabular}

ratio was fixed at 0.5 and 0.46 for YPS-CC and RM-YPS-CC, and the binder, water, and sand were mixed in the ratios of $1: 0.5: 2.86$ and $1: 0.46: 2.86$, respectively. The concretes were prepared based on the Chinese standards GB/T50080 and GB/T50081. The specific operation process is as follows: the concrete mixtures were accurately weighed according to
Tables 4 and 5, and then, they were transferred to a concrete mixer (SJD-15, Shaoxing Shangyu Jeda Instrument Factory, China) for even stirring. The concrete mixtures were placed in the $(100 \times 100 \times 100 \mathrm{~mm})$ molds one at a time and then placed on the platform vibrator $(50 \mathrm{~cm}$, Shaoxing Shangyu Daoxu Feiteng Building Equipment Factory, China) until 
TABLE 5: Mixture proportions of RM-YPS-CC (by weight).

\begin{tabular}{|c|c|c|c|c|c|c|c|c|c|c|c|}
\hline \multirow{2}{*}{ No. } & \multirow{2}{*}{ RM (\%) } & \multirow{2}{*}{ YPS (\%) } & \multirow{2}{*}{ WR (\%) } & \multirow{2}{*}{ FA (\%) } & \multicolumn{7}{|c|}{$1 \mathrm{~m}^{3}$ concrete material composition $(\mathrm{g})$} \\
\hline & & & & & Water & Cement & $\mathrm{RM}$ & YPS & WR & FA & $\mathrm{CA}$ \\
\hline A & 0 & & & & & 375 & 0 & & & & \\
\hline B & 5 & & & & & 350 & 25 & & & & \\
\hline $\mathrm{C}$ & 10 & & & & & 325 & 50 & & & & \\
\hline $\mathrm{D}$ & 15 & 25 & 0.5 & 33 & 230 & 300 & 75 & 125 & 2.5 & 635 & 800 \\
\hline $\mathrm{E}$ & 20 & & & & & 275 & 100 & & & & \\
\hline $\mathrm{F}$ & 25 & & & & & 250 & 125 & & & & \\
\hline G & 30 & & & & & 225 & 150 & & & & \\
\hline
\end{tabular}

the slurry was discharged from the surface. The finished specimens were transferred to a curing box (SHBY-40, Shanghai Jiyi Instrument Factory, China) and then kept at $25^{\circ} \mathrm{C}$ and $95 \%$ of $\mathrm{R}$. H. for $24 \mathrm{~h}$, and the surface of the specimens was covered with an impermeable film. The specimens were maintained for 3 days, 7 days, and 28 days after removing the molds at the same condition to ensure the progress of the hydration reactions, causing the filling and segmentation of the capillary voids by the hydration products under the appropriate temperature and humidity conditions [43].

2.2.2. Measurement of Compressive Strength. Compressive strength was measured by using a hydraulic pressure compression testing machine (YAW-3000B, Zhejiang Yingsong Instrument Equipment Manufacturing Company, China), and the concrete cube compressive strength $\left(f_{\mathrm{cu}}\right)$ was calculated according to the following formula:

$$
f_{\mathrm{cu}}=\frac{F}{A}
$$

where $F$ is the damage load $(\mathrm{N})$ and $A$ is the specimen bearing area $\left(\mathrm{mm}^{2}\right)$.

2.2.3. Microstructure and Composition Tests. The mineral compositions of the hardened pastes of YPS-CC and RMYPS-CC were measured by XRD, and the microstructures of YPS-CC and RM-YPS-CC were measured by SEM to evaluate the effect of RM on concrete to help explain the macroscopic behavior of the concrete.

To prepare the specimens for XRD analysis, concrete cementitious material specimens were produced according to the mix proportions shown in Table 5 (A and C) except for FA and CA and cured for 28 days under standard conditions. The specimens were removed from the standard curing box, dried in the oven, and ground to $-0.075 \mathrm{~mm}$, accounting for $100 \%$. XRD analyses were performed on an X-ray diffraction instrument (X Pert Powder, Panako X-ray Analysis Instruments, Netherlands) with $\mathrm{Cu} \mathrm{K} \alpha$ radiation at $40 \mathrm{~mA}$ and $40 \mathrm{kV}$. A step interval of $0.02^{\circ}$ was selected in a $2 \theta$ range of $5-90^{\circ}$. The specimens for the SEM and EDS analyses were produced according to the mix proportions in Table 5 (A and C). The specimens were removed from the standard curing box after curing for 28 days under standard conditions, dried in the oven, and cut into $5 \mathrm{~mm}$ thick slices. SEM and EDS analyses were carried out on a scanning electron microscope
( IIGMA + X-Max20, Deiss Company, Germany) for examination of the microscopic morphology and structure of the RM-YPS-CC and YPS-CC at the age of 28 days.

2.2.4. Optical Image Acquisition. To evaluate the fracture behavior of the concretes, an image acquisition system containing a hydraulic pressure compression testing machine (YAW-3000B, Zhejiang Yingsong Instrument Equipment Manufacturing Company, China), complementary metal-oxide semiconductor (CMOS) camera, and image acquisition software (MER-500-7UM-L, China Daheng Group Limited Company, China) was designed for the study (Figure 2). The collected images were used to conduct an analysis of the failure morphologies and to conduct a DIC analysis. Natural speckles were adopted because of the optical inhomogeneity on the concrete surface. The setting parameters of the compression testing machine are as follows: a strength grade of C30; a stress velocity of $0.3 \mathrm{MPa} / \mathrm{s}$; and a load speed of $3 \mathrm{KN} / \mathrm{s}$. The white-light images were recorded using a CMOS camera with a time image acquisition speed of $500 \mathrm{msec}$ each time, and a resolution of 5 million pixels was used to calculate the displacement distribution and evolution using the DIC method and to trace the crack initiation or propagation up to fracture failure.

2.2.5. DIC Method. The DIC is a method to obtain the inplane displacement field along the vertical and horizontal directions $(u, v)$ at different positions by searching for the maximum correlation depending on the computation of the gray-level between the selected region of interest in the deformed image $g$ and the reference image $f$. The correlation equation is given by the following formula $[44,45]$ :

$$
C=\frac{\sum_{i=1}^{m} \sum_{j=1}^{m}\left[f\left(x_{i}, y_{j}\right)-\bar{f}\right]\left[g\left(x_{i}^{\prime}, y_{j}^{\prime}\right)-\bar{g}\right]}{\sqrt{\sum_{i=1}^{m} \sum_{j=1}^{m}\left[f\left(x_{i}, y_{j}\right)-\bar{f}\right]^{2} \sqrt{\sum_{i=1}^{m} \sum_{j=1}^{m} g\left(x_{i}^{\prime}, y_{j}^{\prime}\right)-\bar{g}^{2}}}},
$$

where $C$ is the maximum correlation factor, $f(x, y)$ is the gray-level intensity at coordinate $(x, y)$ for the reference image, $g\left(x^{\prime}, y^{\prime}\right)$ is the gray-level intensity at coordinate $\left(x^{\prime}, y^{\prime}\right)$ for the deformed image, $\bar{f}$ is the average gray intensity of the images $f(x, y)$, and $\bar{g}$ is the average gray intensity of the images $g(x, y)$. The size of the selected region of interest is $m \times m$ pixels. 


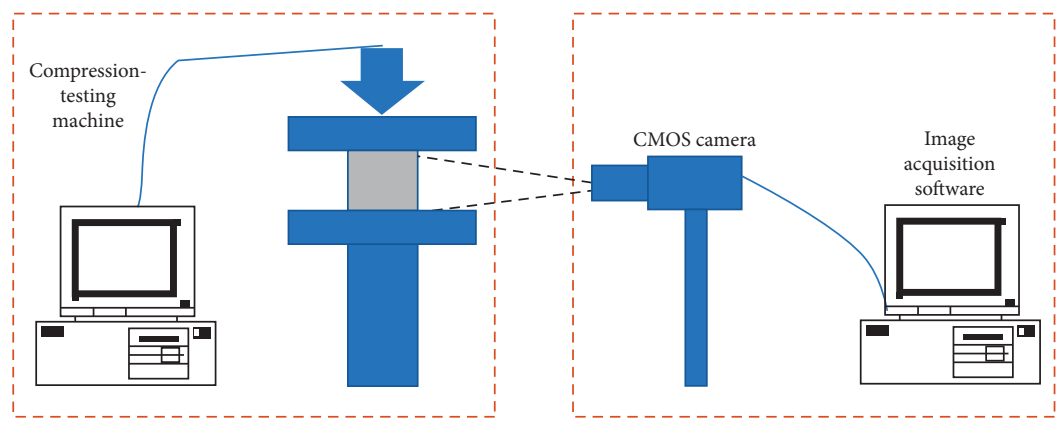

(a)

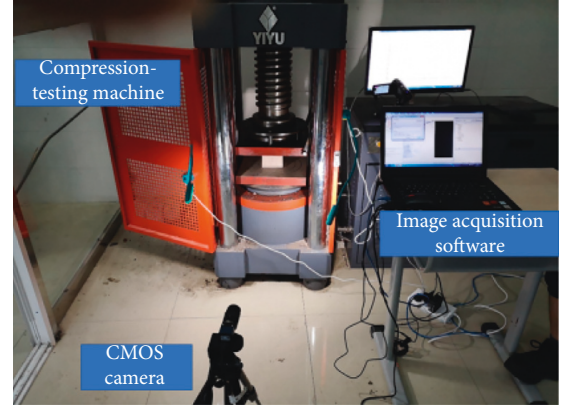

(b)

FIgURE 2: Schematic representation (a) and experimental setup (b) of the of image acquisition system.

In this experiment, the camera lens was adjusted to be parallel to the specimen surface; therefore, the relationship between the coordinates $(x, y)$ and $\left(x^{\prime}, y^{\prime}\right)$ can be expressed as follows [46]:

$$
\left\{\begin{array}{l}
x^{\prime}=x+u+\Delta x \cdot \frac{\partial u}{\partial x}+\Delta y \cdot \frac{\partial u}{\partial y}, \\
y^{\prime}=x+v+\Delta x \cdot \frac{\partial v}{\partial x}+\Delta y \cdot \frac{\partial v}{\partial y},
\end{array}\right.
$$

where $u$ and $v$ are the displacement components for the subset centers in the $x$ and $y$ directions, respectively, and $\Delta x$ and $\Delta y$ are the distances to the point $(x, y)$ from the subset center. The other three parameters $(\partial u / \partial x, \partial v / \partial y$, and $1 / 2(\partial u / \partial y+\partial v / \partial x))$ except for $u$ and $v$ can be obtained using the DIC method. In the experiment, a pixel translated into the size of $33.179 \mu \mathrm{m} /$ pixel, which was experimentally derived.

\section{Results and Discussion}

\subsection{Concrete Compressive Strength Evaluation}

3.1.1. Compressive Strength of the YPS-CC. Figure 3 shows the results of the experiments on the compressive strength of the YPS-CC. The compressive strength increased and then followed a downward trend as the YPSC content ranged from $20 \%$ to $40 \%$ for the ages of both 7 days and 14 days. The strength reached the maximum values of $20.78 \mathrm{MPa}$ and $25.73 \mathrm{MPa}$ at the ages of 7 days and 14 days, respectively, while the YPSC content was 25\%, and it decreased gradually as the YPSC increased and exceeded the maximum value. These results indicated that YPSC had a great influence on the strength of the concrete, and $25 \%$ might be the appropriate content. In addition, the pozzolanic effects of the YPS were enhanced in the concrete as the curing age increased, and the YPS was beneficial to the development of the long-term strength of the concrete [4]. The compressive strength of the concretes using all the YPSC did not reach 29.1 MPa (compressive strength of pure cement in Table 1 ) at the age of 3 days because the residual $\mathrm{P}_{2} \mathrm{O}_{5}$ in the YPS had a strong retarding effect on the setting time and because the insufficient $\mathrm{Al}_{2} \mathrm{O}_{3}$ content affected the early strength properties [31]. The cementing effect of the YPS was not as strong as that of the cement, and the YPS contained residual

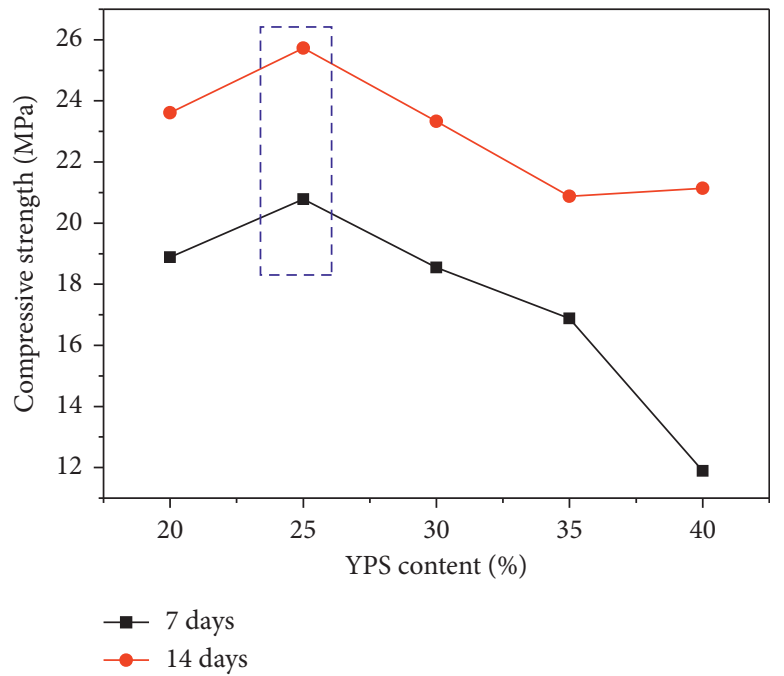

Figure 3: Compressive strength of concrete (7 and 14 days of curing) as a function of substituting YPSC for cement.

phosphorus in the form of $\mathrm{P}_{2} \mathrm{O}_{5}$; therefore, it was beneficial to add other materials to improve the alkalinity or inhibit the negative impact of the phosphorus on the mechanical properties. In the experiments described in Section 3.1.2, RM was used to investigate the synergistic effects on RM-YPSCC based on high alkali and high aluminum contents in RM.

3.1.2. Compressive Strength of RM-YPS-CC. Variations in the compressive strength of the RM-YPS-CC versus the content of cement replacement by RM under the condition of $25 \%$ YPSC at the ages of 3, 7, and 28 days are presented in Figure 4, in which the horizontal dotted line represents the minimum control values $(28.5 \mathrm{MPa})$ according to the Chinese standard GB/T50107-2010. Obviously, the presence of RM significantly changed the mechanical properties of the concrete. Figure 4 shows that the strength of development at 3 days and 7 days was very similar except with RMC15. In general, RMC0 had the highest strength and presented a downward trend as the content of RM increased, which was probably because the setting times of the RM and YPS were longer than those of the cement and because the reaction in the RM-YPS-CC was not complete within 7 days. The compressive strength increased as the RMC content increased 


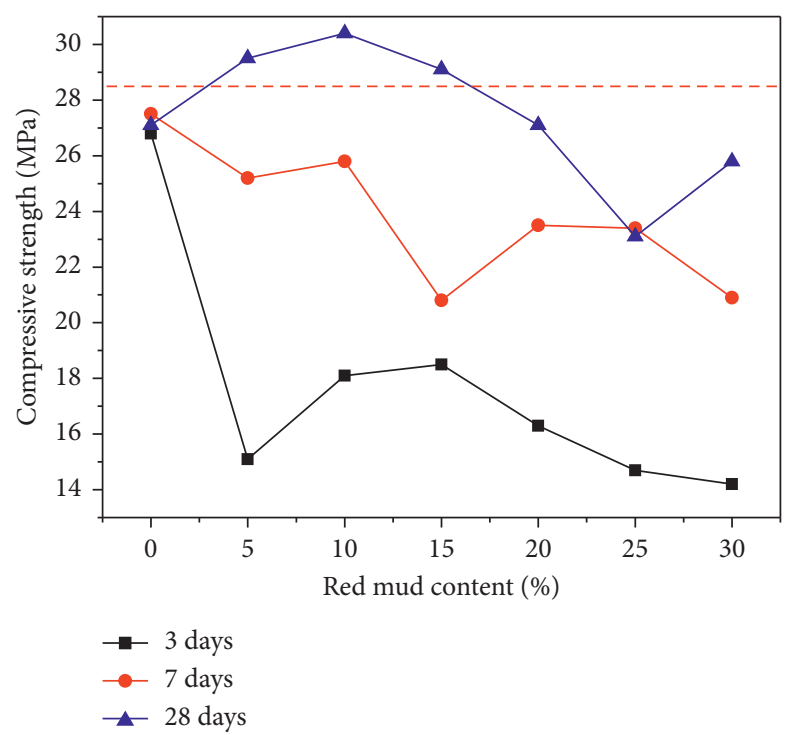

Figure 4: Compressive strength of concrete $(3,7$, and 28 days of curing) as a function of substituting RMC for cement (for $25 \%$ YPSC).

in the range of less than RMC15 and decreased in the range of more than RMC15 at the age of 28 days, which was consistent with the previous studies conducted by Ribeiro and Labrincha [47]. These results might be attributable to a considerable amount of alkaline substances in $\mathrm{RM}$, raising the $\mathrm{pH}$ of the cementing mixture to stimulate the YPS activation and releasing more calcium hydroxide during hydration and producing greater cementitious properties in a certain range of RM content. Moreover, concrete compressive strength increased gradually in the case of higher iron levels in the concrete mix from the research studies performed by Tang et al. [34] and Alzaed [48]; therefore, the higher iron levels of RM may help improve the compressive strength. However, the pozzolanic properties of the RM were lower than those of Portland cement, and there was greater water absorption as the RM content was increased [13]; therefore, the compressive strength decreased after RMC15. The compressive strength met the standard for RMC5, RMC10, and RMC15, and it reached its highest value for RMC10 higher than that in the previous studies, showing that the RMC was usually less than $5 \%$ in cement prepared from RM [49-51].

\subsection{Role of RM in the Microstructure Formation of $R M-Y P S-C C$}

3.2.1. XRD Analysis. To study the influence of RM on concrete, the mineral composition of cementitious materials in the specimens was determined by XRD, which provided insight into the microstructure of the concrete and explained why the RM-YPS-CC had superior mechanical properties compared with the YPS-CC. Figure 5 presents the XRD of the cementitious materials in the concrete specimen and the raw materials. The XRD results show that the main mineral phase of the YPS was vitreous because there was insufficient

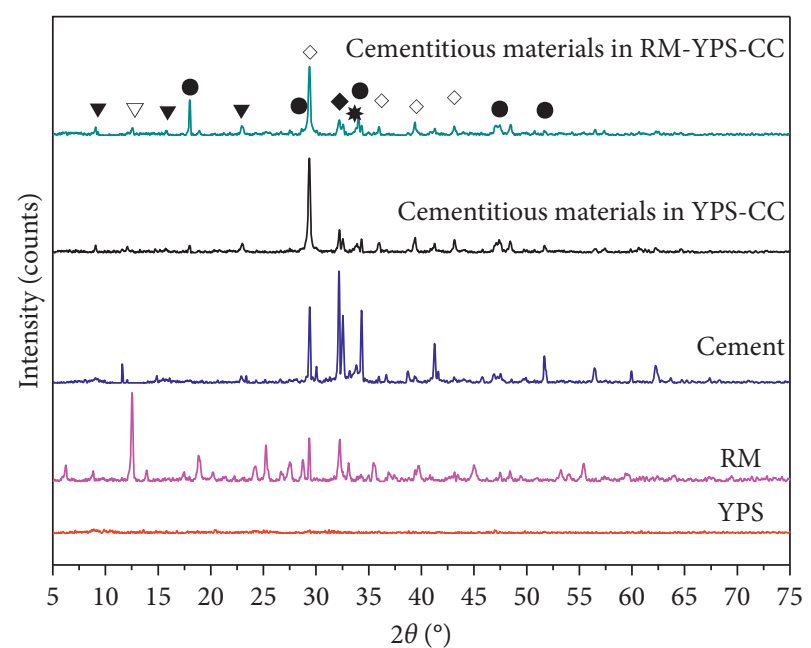

FIGURE 5: XRD results of the cementitious materials in concrete specimens RM-YPS-CC, YPS-CC, cement, RM, and YPS. V: ettringite (AFt, $3 \mathrm{CaO} \cdot \mathrm{Al}_{2} \mathrm{O}_{3} \cdot 3 \mathrm{CaSO}_{4} \cdot 32 \mathrm{H}_{2} \mathrm{O}, \mathrm{PDF} \# 41-1451$ ); •: portlandite $\left(\mathrm{CH}, \mathrm{Ca}(\mathrm{OH})_{2}, \mathrm{PDF} 444-1481\right) ; \diamond$ : calcite $\left(\mathrm{CaCO}_{3}\right.$, PDF\#47-1743); $\nabla$ : tricalcium silicate $\left(\mathrm{C}_{3} \mathrm{~S}, 3 \mathrm{CaO} \cdot \mathrm{SiO}_{2}, \mathrm{PDF} 449-\right.$ 0442); tricalcium aluminate $\left(\mathrm{C}_{3} \mathrm{~A}, 3 \mathrm{CaO} \cdot \mathrm{Al}_{2} \mathrm{O}_{3}, \mathrm{PDF} 06-0495\right)$; *: dicalcium silicate $\left(\beta-\mathrm{C}_{2} \mathrm{~S}, 2 \mathrm{CaO} \cdot \mathrm{SiO}_{2}, \mathrm{PDF} \# 33-0302\right)$.

time for crystallization and a large number of amorphous active reticular or glass structures were formed inside the YPS when the phosphorus slag was treated by water quenching from the high-temperature amorphous melt $[52,53]$. There was a great quantity of calcium aluminum oxide in the RM, which could promote the generation and growth of the cementing materials. Compared with the XRD results of the cementitious materials in the YPS-CC specimen, the intensity of the portlandite $(\mathrm{CH})$ characteristic peak $\left(2 \theta \approx 18^{\circ}\right.$, according to PDF\#44-1481) of the RM-YPSCC was significantly enhanced and the intensity of the ettringite $(\mathrm{AFt})$ characteristic peak $\left(2 \theta \approx 23^{\circ}\right.$, according to PDF\#41-1451) was also enhanced to a certain extent; these were the main cementing materials in the cement binder [41]. These results might have occurred because the RM contained a great quantity of calcium oxide, aluminum silicate, and alkaline substances that stimulated the YPS activation to induce the secondary pozzolanic reaction. In addition, the solubility of the calcium hydroxide decreased in the high-alkali environment [54], and the newly formed $\mathrm{CH}$ would have precipitated rapidly, which might have led to the formation of $\mathrm{CH}$ crystals in the concrete. The equations of chemical reactions of $\mathrm{CH}$ and $\mathrm{Aft}$ are as follows [55]:

$$
\begin{array}{r}
2 \mathrm{C}_{3} \mathrm{~S}+11 \mathrm{H} \longrightarrow \mathrm{C}_{3} \mathrm{~S}_{2} \mathrm{H}_{8}+3 \mathrm{CH} \\
2 \mathrm{C}_{2} \mathrm{~S}+9 \mathrm{H} \longrightarrow \mathrm{C}_{3} \mathrm{~S}_{2} \mathrm{H}_{8}+\mathrm{CH} \\
\mathrm{C}_{3} \mathrm{~A}+3 \mathrm{C} \overline{\mathrm{S}} \mathrm{H}_{2}+26 \mathrm{H} \longrightarrow \mathrm{C}_{6} \mathrm{AS}_{3} \mathrm{H}_{32}
\end{array}
$$

where in cement chemistry notation, $\mathrm{C}_{3} \mathrm{~S}$ is tricalcium silicate, $\mathrm{H}$ is water, $\mathrm{C}_{3} \mathrm{~S}_{2} \mathrm{H}_{8}$ is calcium silicate hydrate, $\mathrm{C}_{2} \mathrm{~S}$ is 
dicalcium silicate, $\mathrm{C}_{3} \mathrm{~A}$ is tricalcium aluminate, $\mathrm{C} \overline{\mathrm{S}} \mathrm{H}_{2}$ is gypsum, and $\mathrm{C}_{6} \mathrm{~A}_{3} \mathrm{H}_{32}$ is AFt. $\mathrm{CH}$ and AFt were beneficial to mechanical properties of the concrete.

3.2.2. SEM and EDS Analysis. Hardened concrete consists of three components, including the aggregate, interfacial transition zone (ITZ), and cement paste. The ITZ, the region between the hardened cement paste and the aggregate, is recognized as a high correlate to the mechanical strength [34]. The SEM images of the ITZ morphology and the hardened cement paste characteristics are presented in Figure 6. All the ITZs in the YPS-CC and RM-YPS-CC had microcracks with different widths, which indicated that the cementitious materials in the concrete had shrunk to a certain extent at the age of 28 days of the curing period. Comparison of the SEM images of the ITZ in the YPS-CC and RM-YPS-CC (Figures 6(a) and 6(b)) shows that there was not a significant difference between them in terms of the porosity and crack width.

Comparison of the structures and morphologies of the cement pastes shows there was a large difference between the RM-YPS-CC and YPS-CC. Figures 6(c) and 6(d) show the morphologies within the cementitious materials in the RM-YPS-CC and YPS-CC, respectively. Compared with the YPS-CC, the cementitious materials in the RM-YPS-CC were more interlaced and had more micropores inside them and there was more disorder in the crystals of the RM-YPS-CC, which formed a more complex spatial structure. EDS was performed to investigate the chemical composition of the hardened cement pastes of the samples. Figures $7(\mathrm{a})$ and $7(\mathrm{~b})$ present the locations of the EDS analyses on the RM-YPS-CC and YPS-CC, respectively. The quantitative results of the elemental analysis of the cementing materials in the RM-YPS-CC and YPS-CC are presented in Table 6 . The results in Table 6 show that more elemental $\mathrm{Al}$ was entrained into the cementitious materials by adding RM, which was beneficial for promoting the formation of AFt.

3.3. Destruction Image of the RM-YPS-CC. The whole failure process of the RM-YPS-CC under different applied loads was recorded using a CMOS camera. Figure 8 shows the binary images of the failure morphologies on the concrete surfaces at the maximum compressive strength at 28 days with different contents of RM. The topographies were highly relevant to the RMC. The microcracks on the failure morphology of the concrete without RM were chaotic, and there were many transverse microcracks compared with those of the specimen with RM.

Figure 9 shows the relationships among the compressive strength, the initial cracking strength, and the amount of RMC added to the concrete cured for 28 days. The change trend of the initial cracking strength was the same as that of the compressive strength. However, the change in the initial cracking strength was more obvious than that of the compressive strength.
The crack number and maximum crack width as a function of RMC for curing 28 days are shown in Figure 10. The crack number and maximum crack width showed almost the same trends. The maximum crack width reached $3.96 \mathrm{~mm}$, and the crack number was 8 with RMC0, while the maximum crack width was $0.66 \mathrm{~mm}$ and the crack number was 3 with RMC15, which was in agreement with the previous studies. The obvious trend indicated the RM stimulated the performance of the concrete.

\subsection{Distribution and Evolution of the Displacement}

3.4.1. YPS-CC. The DIC method was employed to calculate the field displacement of the concrete surfaces at different loading levels. Figure 11 shows the distribution and evolution of the horizontal and vertical displacements $(u, v)$ of the first crack area on the YPS-CC surface (in the red box of image 1) after 28 days under an applied load. It is obvious from Figure 11(a) that the displacement distribution was symmetric along the vertical direction and uniform along the horizontal direction, with the exception of a few small areas in which the applied load increased from $0 \mathrm{MPa}$ to $5 \mathrm{MPa}$, which was a kind of elastic deformation characterization [46]. The horizontal and vertical displacements for an increase in the applied load to $10 \mathrm{MPa}$ are shown in Figure 11(b). The displacement distribution changed quickly at $10 \mathrm{MPa}$ for both the horizontal and vertical directions and maintained a similar trend from $10 \mathrm{MPa}$ to $27.1 \mathrm{MPa}$ (compressive strength value), as shown in Figures 11(b)11(f), which indicated that local irreversible fractures appeared inside the concrete at $10 \mathrm{MPa}$. While the applied load reached 27.1 MPa, the distribution of displacement tended to be uniform along the vertical direction, which may have occurred because all parts of the specimen had been destroyed at 27.1 MPa. The distribution and evolution of the macroscopic cracks could also support the above conclusions, as shown in images Figures 11(a)-11(f).

3.4.2. RM-YPS-CC. Figure 12 shows the distribution and evolution of the horizontal and vertical displacements $(u, v)$ of the first crack area and the surface topographies on the RM-YPS-CC surface (in the red box of image 1) at the age of 28 days under the applied load of $5 \mathrm{MPa}, 10 \mathrm{MPa}$, $15 \mathrm{MPa}, 20 \mathrm{MPa}, 25 \mathrm{MPa}$, and $30 \mathrm{MPa}$. There were small distribution and evolution of the horizontal and vertical displacements; however, there was little change in those from $5 \mathrm{MPa}$ to $25 \mathrm{MPa}$, as shown in Figures 12(a)-12(e). Therefore, the surface and internal structure of the concrete were almost undamaged under the applied load of $25 \mathrm{MPa}$. When the applied load reached $30 \mathrm{MPa}$, the distribution of the displacement changed rapidly along the horizontal direction. Thus, a local irreversible fracture appeared inside the concrete. The analysis of the surface morphology in Figures 12(a)-12(f) was consistent with the aforementioned results. The RM-YPS-CC clearly had a greater resistance to failure and a better cohesive capability inside than did the YPS-CC. 


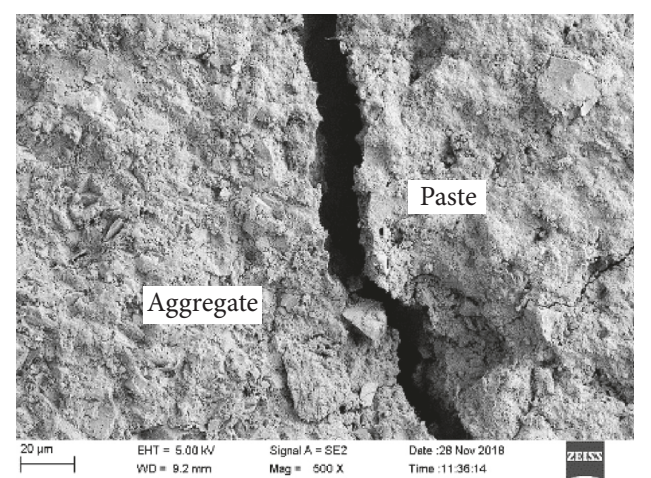

(a)

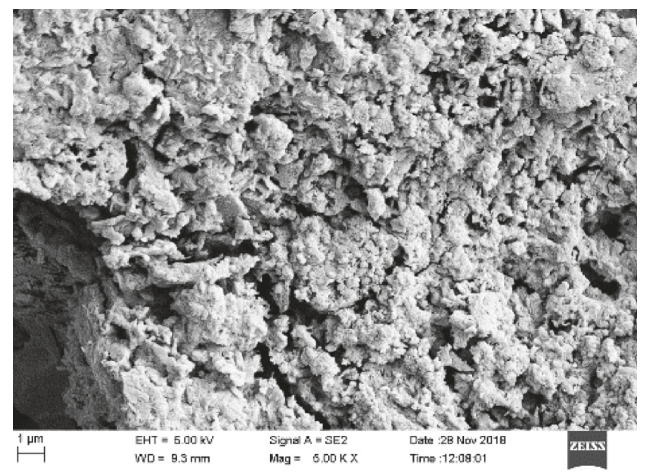

(c)

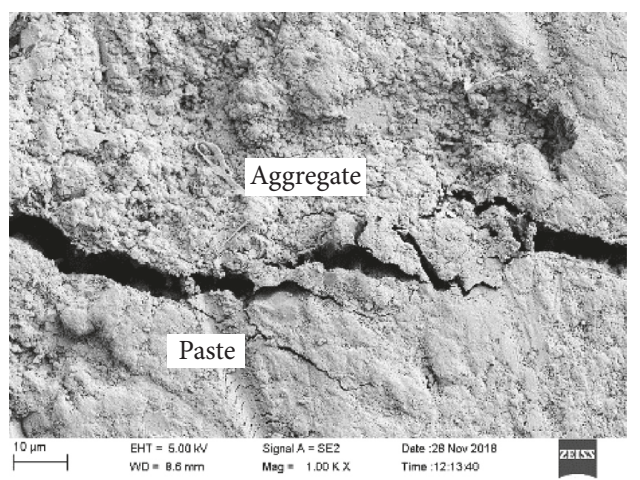

(b)

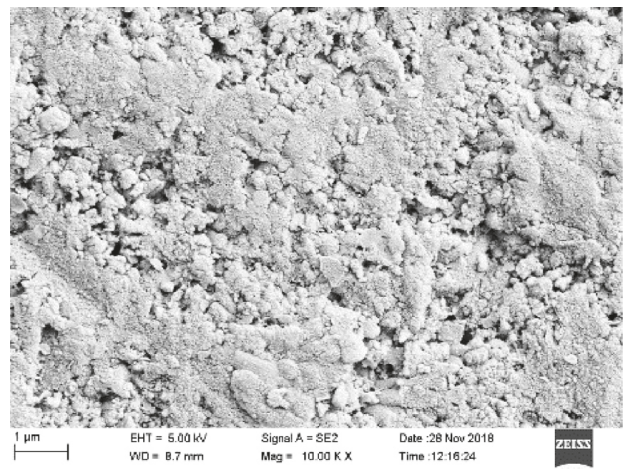

(d)

FIGURE 6: SEM images of interfacial transition zone in (a) RM-YPS-CC and (b) YPS-CC and the paste in (c) RM-YPS-CC and (d) YPS-CC.

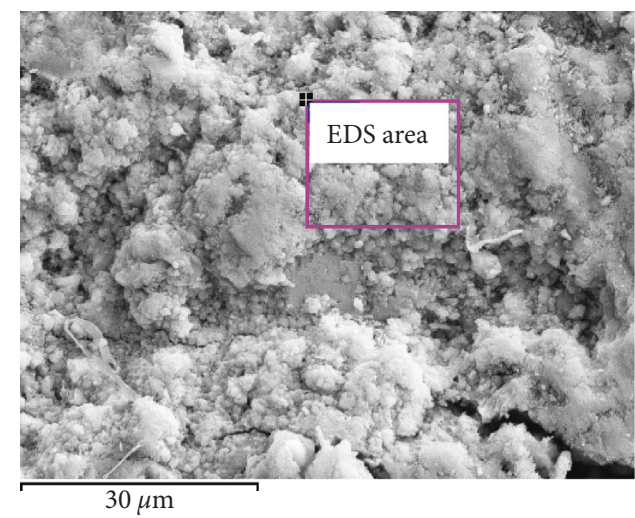

(a)

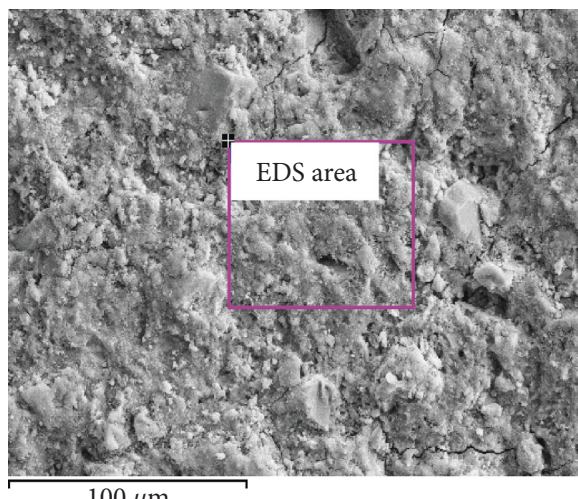

(b)

Figure 7: EDS locations for paste in (a) RM-YPS-CC and (b) YPS-CC.

TABLE 6: EDS chemical compositions of hardened concrete pastes (average).

\begin{tabular}{lcc}
\hline Element & & Weight (\%) \\
\hline $\mathrm{C}$ & RM-YPS-CC & YPS-CC \\
$\mathrm{O}$ & 13.43 & 14.95 \\
$\mathrm{Mg}$ & 49.93 & 49.60 \\
$\mathrm{Al}$ & 0.76 & 0.37 \\
$\mathrm{Si}$ & 1.95 & 0.61 \\
$\mathrm{~K}$ & 6.01 & 2.12 \\
$\mathrm{Ca}$ & 0.31 & 0.52 \\
\hline
\end{tabular}




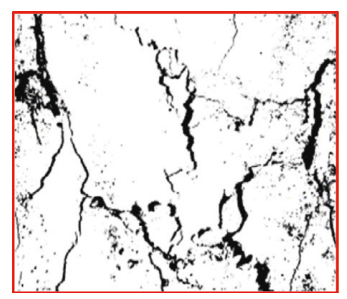

(a)

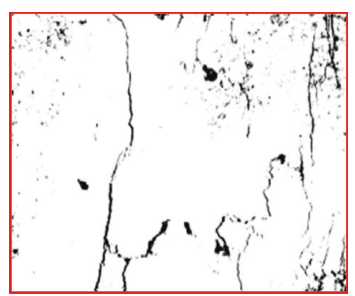

(e)

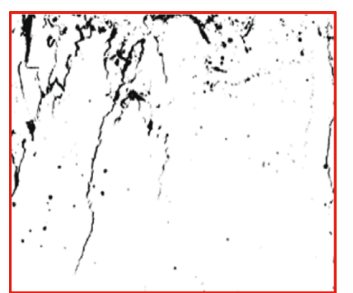

(b)

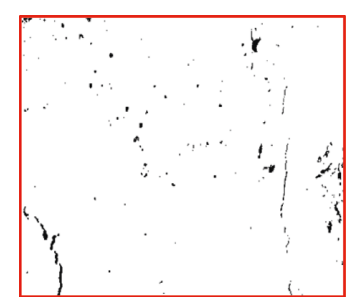

(c)

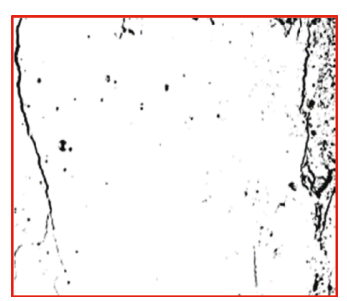

(d)

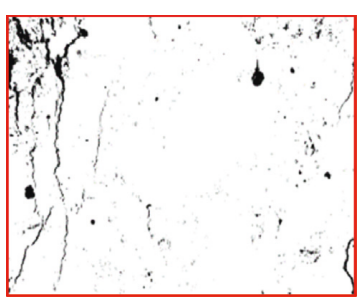

(f)

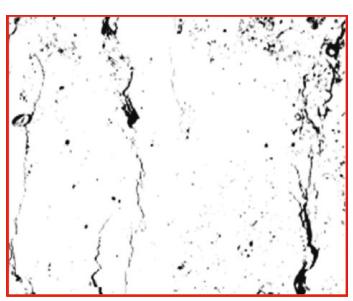

(g)

FIGURE 8: Failure binary images of the concrete at the maximum compressive strength with different RMC contents: (a) $0 \%$, (b) $5 \%$, (c) $10 \%$, (d) $15 \%$, (e) $20 \%$, (f) $25 \%$, and (g) $30 \%$.

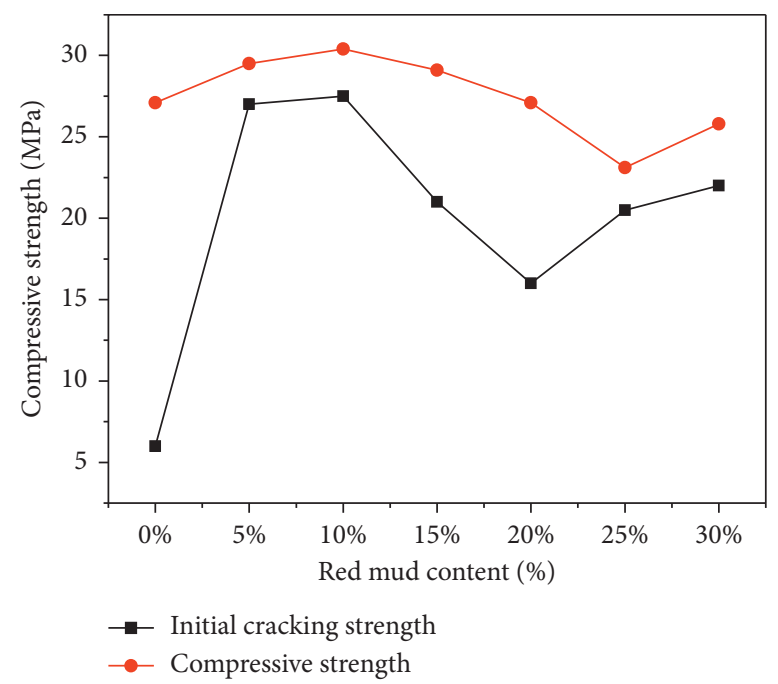

FIGURE 9: Compressive strength and initial cracking strength as a function of RMC added to concrete cured for 28 days.

\section{Conclusions}

The following conclusions were derived from the study of the RM-YPS-CC preparation and the fracture behavior of the RM-YPS-CC under different loading conditions:

(1) Concrete prepared with the addition of $25 \%$ YPSC and $10 \%$ RMC to partially replace the cement at the age of 28 days could meet the mechanical property requirements. More $\mathrm{AFt}$ and $\mathrm{CH}$ were generated, the cementitious materials were more interlaced, and there was more disorder in the crystals of the RMYPS-CC, which formed a more complex spatial structure than those in the YPS-CC, as demonstrated by XRD, SEM, and EDS. The research aimed to achieve wide application of YPS and RM to save energy and reduce $\mathrm{CO}_{2}$ emission.
(2) By studying the shape, size, and number of cracks and initial cracking strength on the surface of the concrete, we found that RM had an excellent adhesive ability on RM-YPS-CC. The RM inhibited the appearance of concrete surface cracks and optimized the surface morphology of the concrete. Without $\mathrm{RM}$, the initial cracking strength was 5-6 MPa, the maximum crack width was $3.96 \mathrm{~mm}$, and the crack number was 8 . However, the cracking strength was 26.5-27 MPa with RMC5, the maximum crack width was $0.66 \mathrm{~mm}$ with $\mathrm{RMC} 15$, and the crack number was 3 with RMC15.

(3) Studies by the DIC method indicated that the RMYPS-CC had a greater resistance to failure and a better cohesive capability inside than did the YPS-CC. For the YPS-CC, the displacement distribution and 


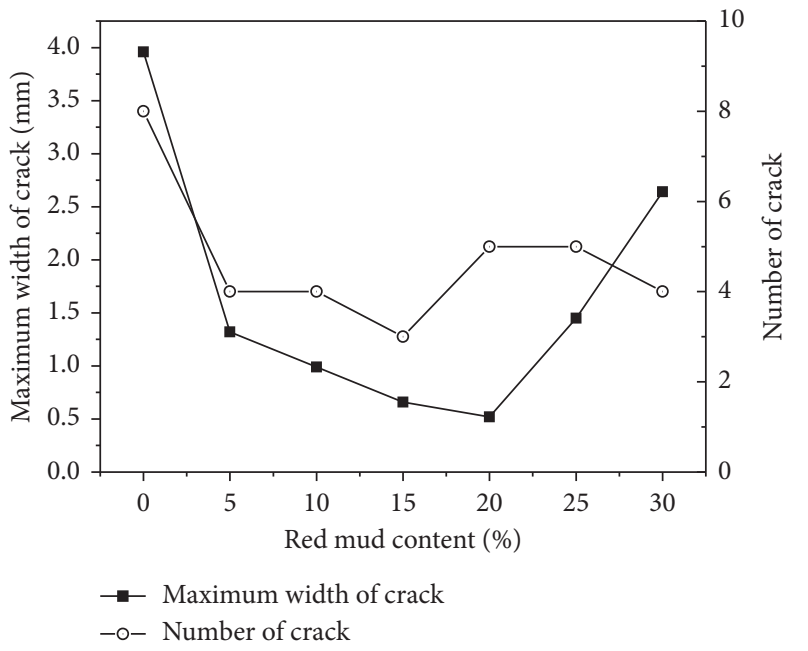

FIGURE 10: Crack number and maximum crack width as a function of RMC added to concrete cured for 28 days.

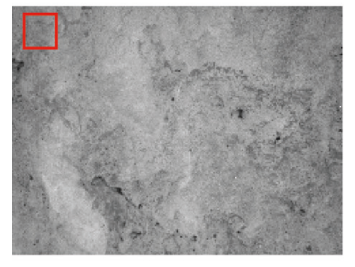

Image 1

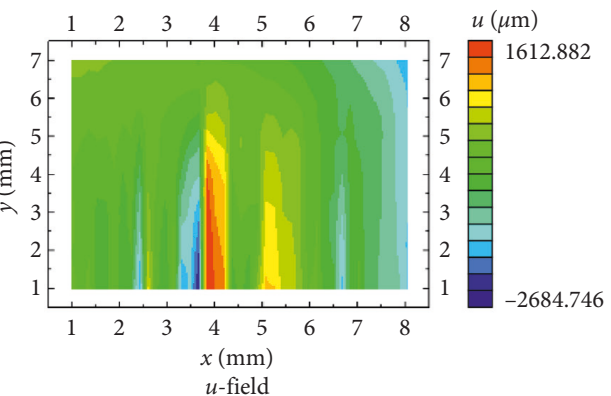

(a)

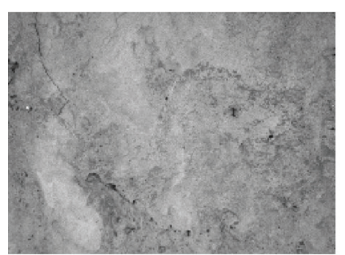

Image 2

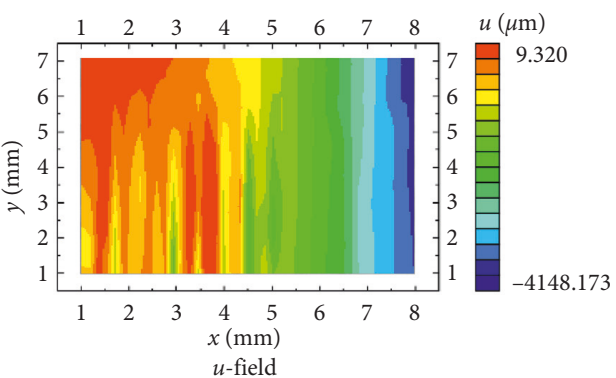

(b)

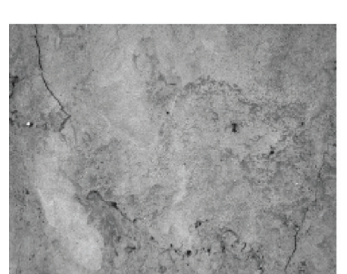

Image 3

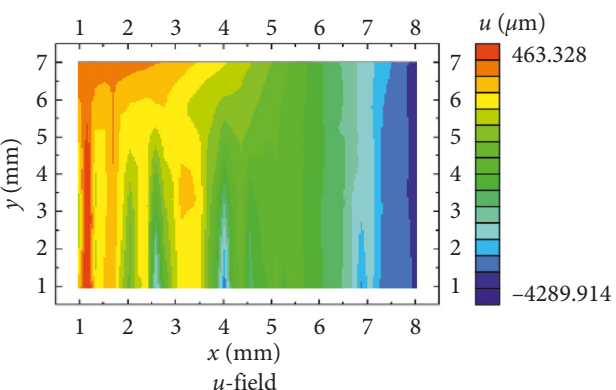

(c)
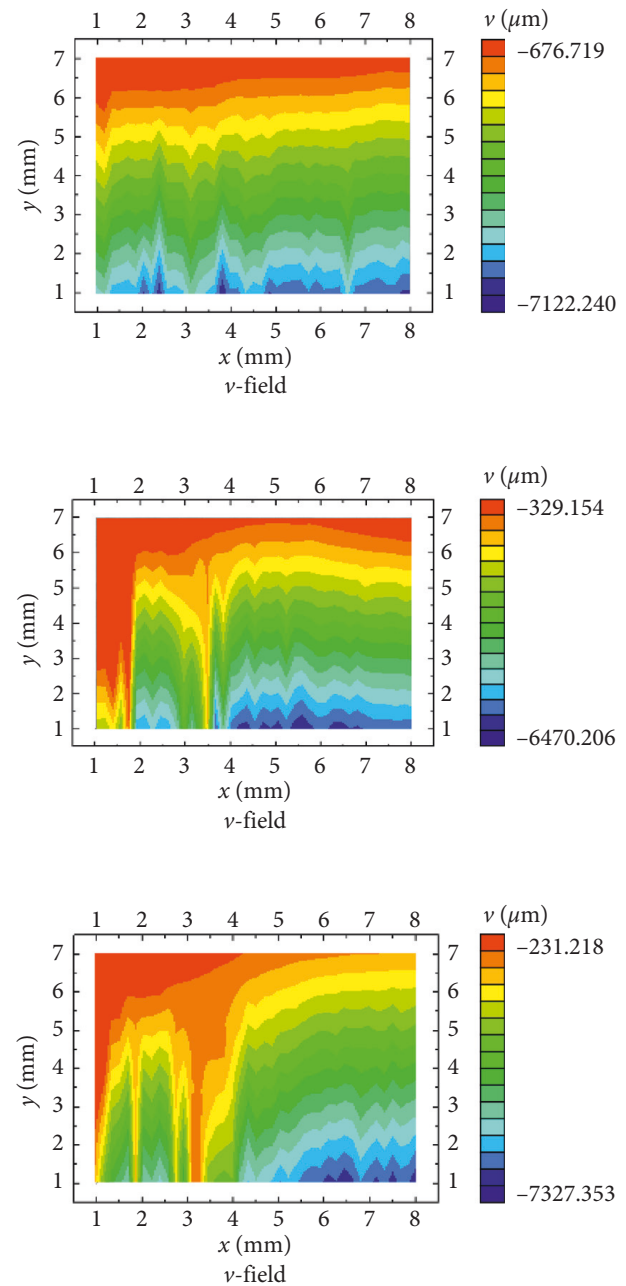

Figure 11: Continued. 


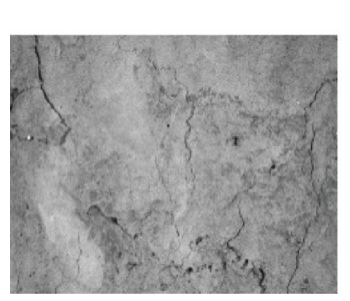

Image 4

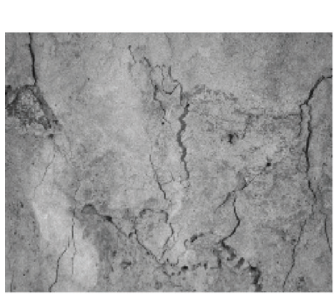

Image 5

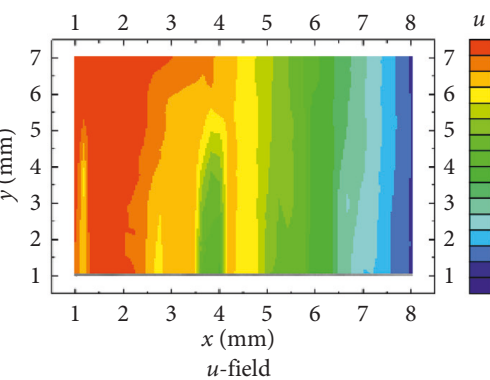

(d)

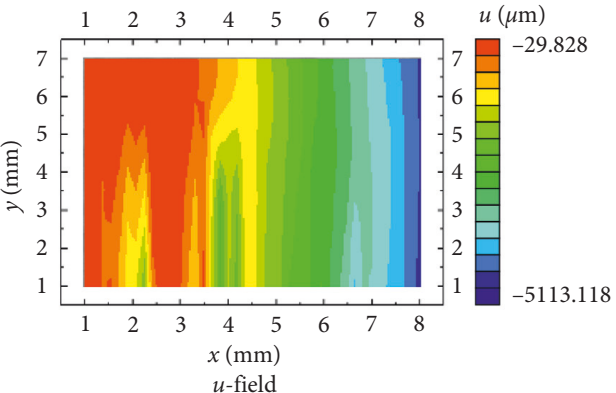

(e)

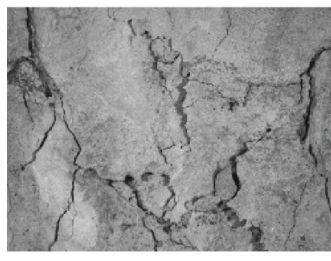

Image 6

$u(\mu \mathrm{m})$

$-180.726$

$u(\mu \mathrm{m})$
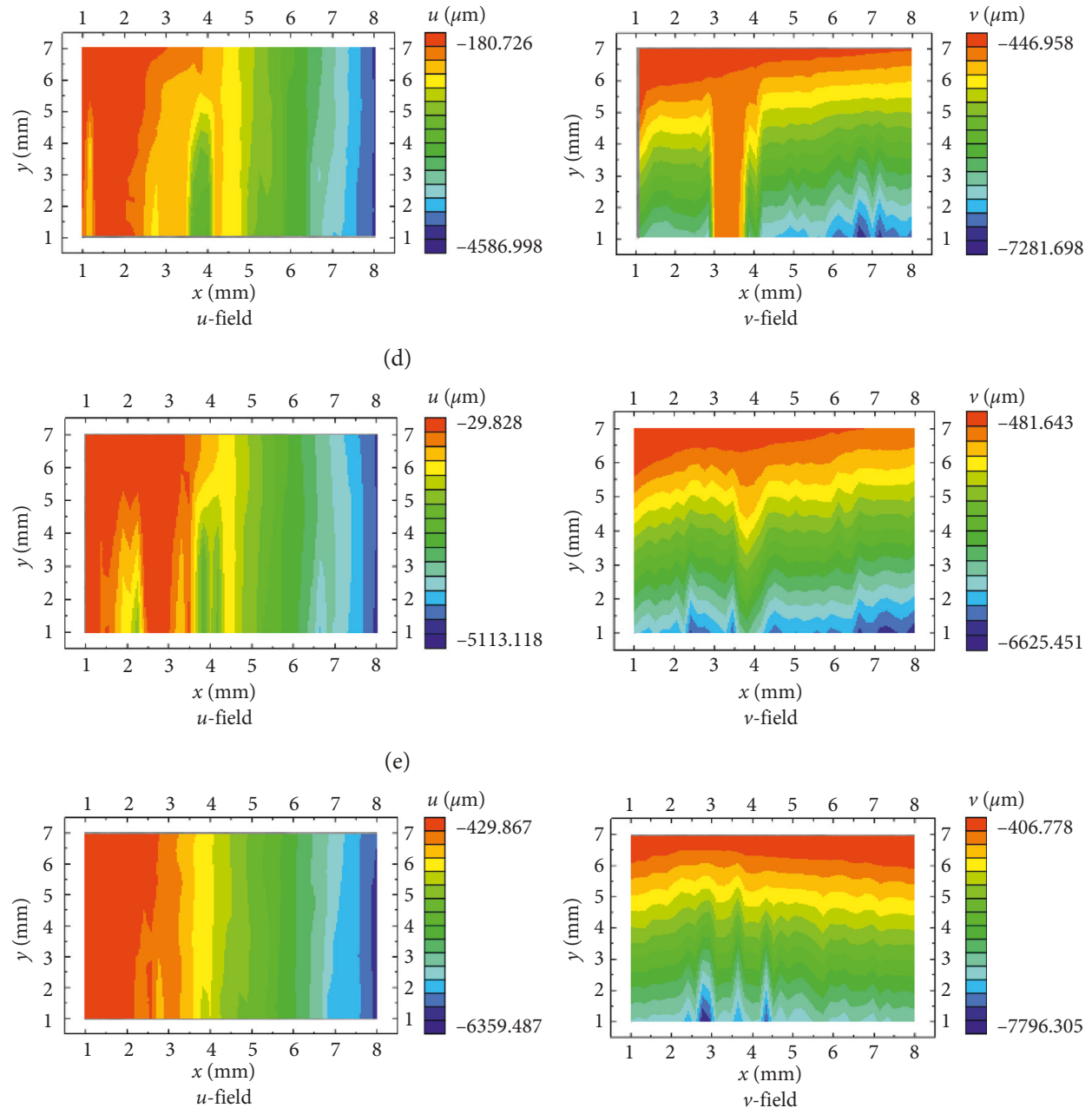

(f)

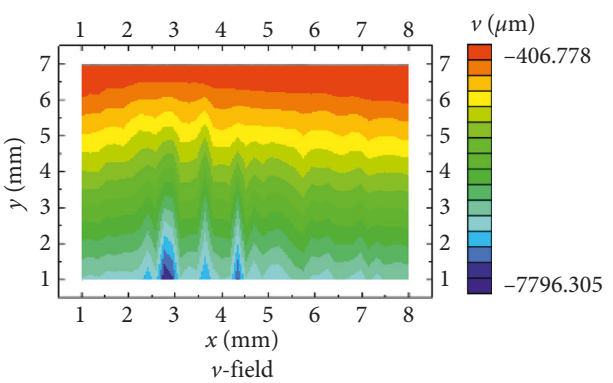

FIgURE 11: The field displacement $(u, v)$ of the first crack area and surface topographies on the YPS-CC surface at the age of 28 days under (a) $5 \mathrm{MPa}$; (b) $10 \mathrm{MPa}$; (c) $15 \mathrm{MPa}$; (d) $20 \mathrm{MPa}$; (e) $25 \mathrm{MPa}$; and (f) $27.1 \mathrm{MPa}$.

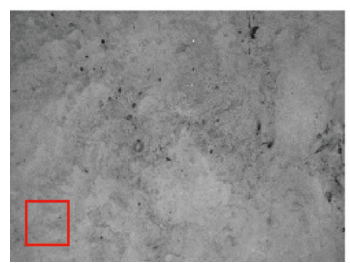

Image 1

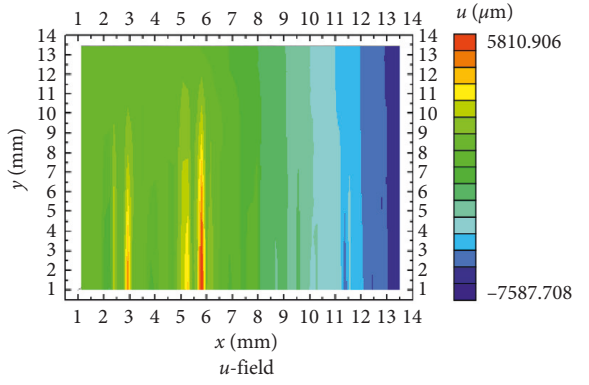

(a)

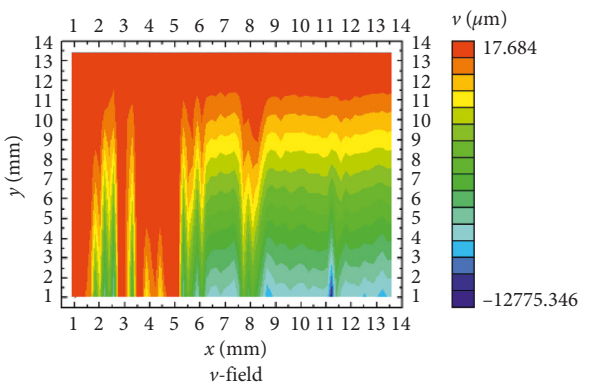

Figure 12: Continued. 


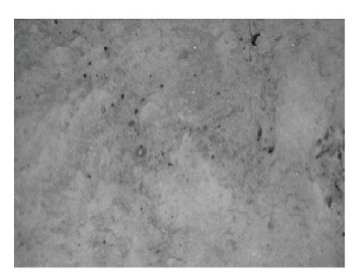

Image 2

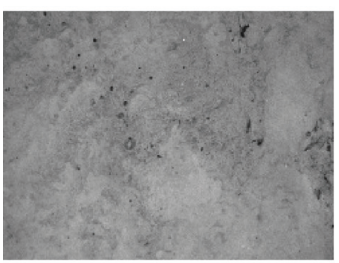

Image 3

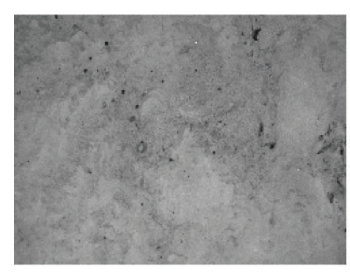

Image 4

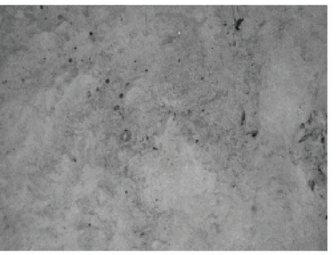

Image 5

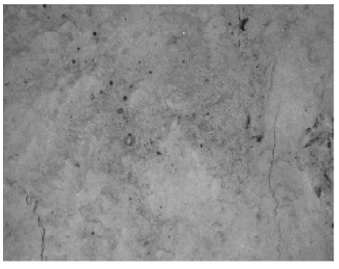

Image 6

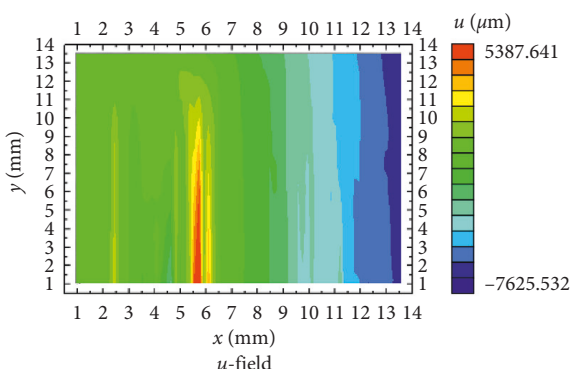

(b)

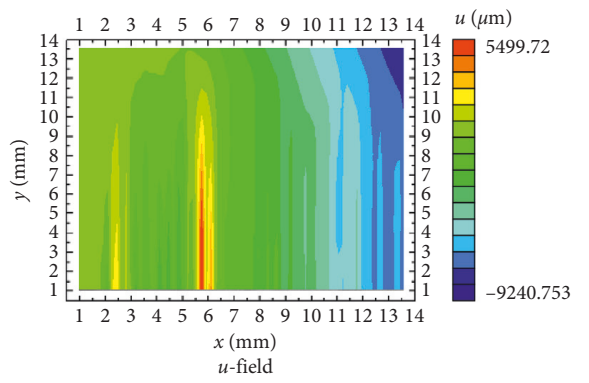

(c)

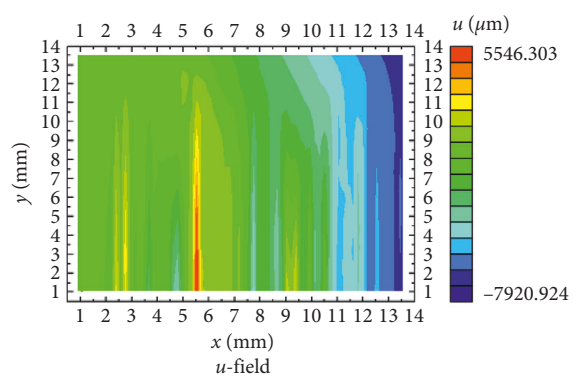

(d)

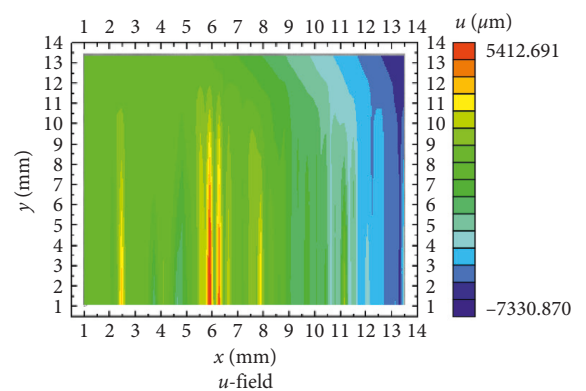

(e)

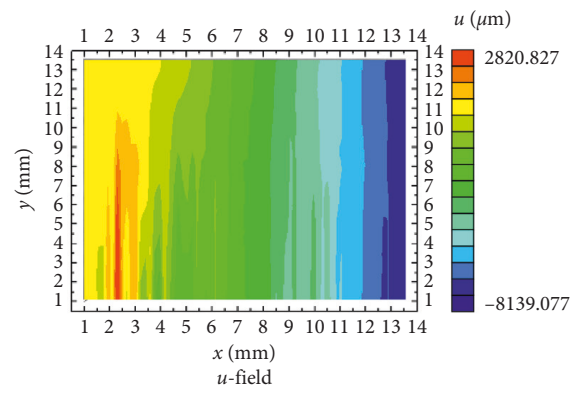

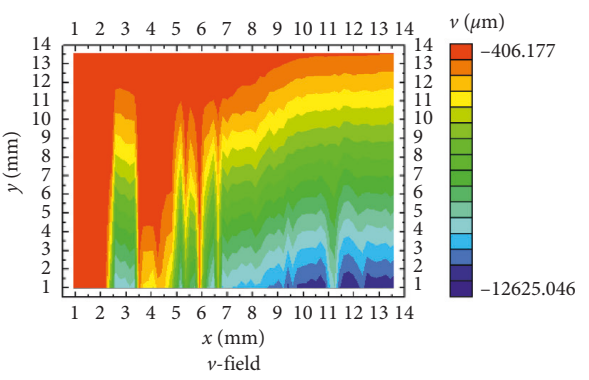
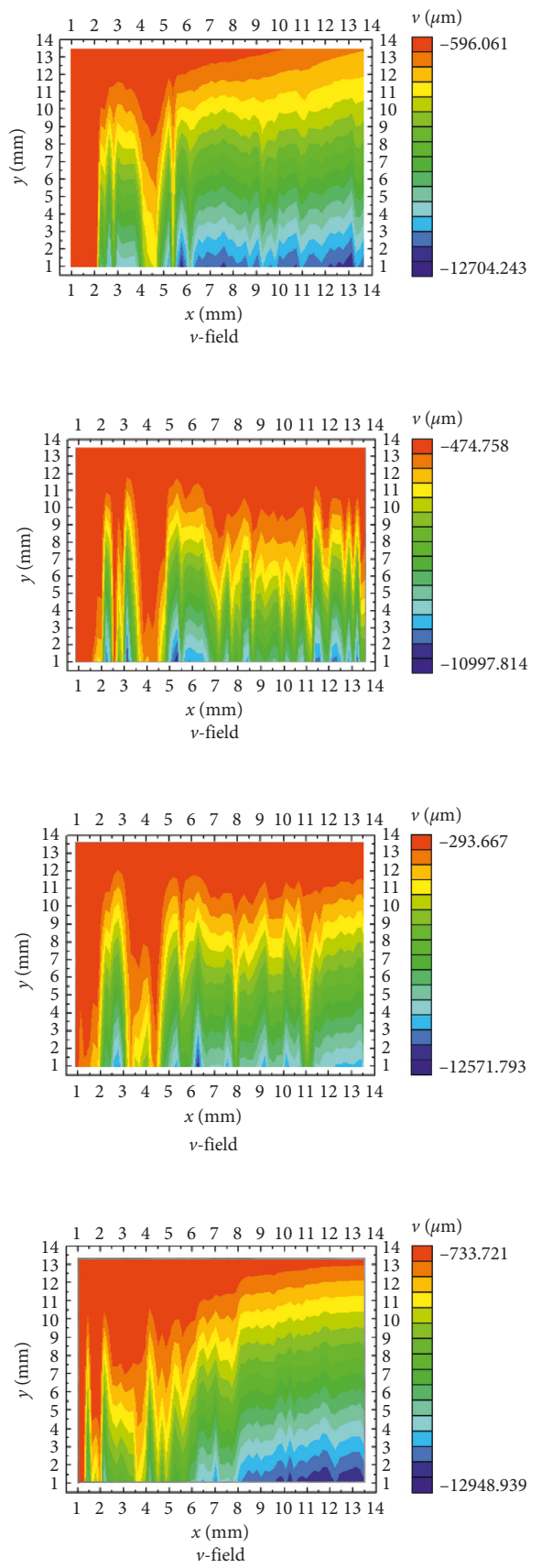

(f)

FIGURE 12: The field displacement $(u, v)$ of the first crack area and surface topographies on the RM-YPS-CC surface at the age of 28 days under (a) $5 \mathrm{MPa}$; (b) $10 \mathrm{MPa}$; (c) $15 \mathrm{MPa}$; (d) $20 \mathrm{MPa}$; (e) $25 \mathrm{MPa}$; and (f) $30 \mathrm{MPa}$. 
evolution of the first crack area changed quickly at $10 \mathrm{MPa}$ for both the horizontal and vertical directions and maintained a similar trend from $10 \mathrm{MPa}$ to 27.1 MPa. For the RM-YPS-CC, there were small distribution and evolution of the horizontal and vertical displacements from $5 \mathrm{MPa}$ to $25 \mathrm{MPa}$, and they changed rapidly and reached $30 \mathrm{MPa}$.

\section{Data Availability}

All data generated or analyzed during this study were finished in Guizhou University and were included in this paper.

\section{Conflicts of Interest}

The authors declare that there are no conflicts of interest regarding the publication of this paper.

\section{Acknowledgments}

Much of this research would not have been possible without the generous support and grant from the High-Level of Innovative Talents of Guizhou Province, China (Project [2015]4012) and the Science and Technology Support Program of Guizhou Province, China (Qian Ke He Support [2017] 2040). The researchers would like to acknowledge the support and contributions of all the people listed. The authors are grateful to Prof. Xuefeng Yao, Dr. Wei Liu, and Shen Wang, PhD candidate, from the Tsinghua University, for providing assistance with the DIC experiments and the theoretical analysis, Xianhai Li and Qin Zhang, who helped design the experiments, Qin Zhang, who provided the resources for the experiments, Xianhai Li, who conducted the experiments, Song Mao, Longjiang $\mathrm{Li}$, and Jingbo Wang, who helped analyze some data, and Xianhai Li, who completed the paper writing.

\section{Supplementary Materials}

File 1: graphical abstract representing the difference of displacement distribution and evolution of the first crack area in horizontal or vertical direction between the two kinds of concretes (yellow phosphorous slag-cement concrete and red mud-yellow phosphorous slag-cement concrete). For yellow phosphorous slag-cement concrete, the displacement distribution and evolution changed obviously to $15 \mathrm{MPa}$ from $5 \mathrm{MPa}$ either in horizontal or vertical direction, and the specimen had been destroying at 27.1 MPa. For red mud-yellow phosphorous slag-cement concrete, a small distribution and evolution of horizontal or vertical displacement occurred from $5 \mathrm{MPa}$ to $15 \mathrm{MPa}$, and it would change rapidly when reaching $30 \mathrm{MPa}$. Moreover, graphical abstract showed the reason for the better mechanical properties of red mud-yellow phosphorous slagcement concrete was the existence of red mud led to more ettringite $(\mathrm{AFt})$ and calcium hydroxide $(\mathrm{CH})$ in concrete, which had proved to be an effective cementitious material and promoted beneficial changes in the spatial structure of cementitious material. File 2: highlight 1: qualified concrete prepared with up to $10 \%$ of red mud and $25 \%$ of yellow phosphorus slag. In the research, concrete prepared by adopting $25 \%$ yellow phosphorus slag content and $10 \%$ red mud content to replace part of cement at the age of 28 days could meet the requirement of mechanical properties, which provided some ideas for wide application of yellow phosphorus slag and red mud in energy-saving and emission reduction. Highlight 2: displacement distribution and evolution of the first crack area using DIC measurement. In the research, the displacement distribution and evolution of the first crack area of yellow phosphorous slag-cement concrete and red mud-yellow phosphorous slag-cement concrete under different applied load levels were studied by digital image correlation (DIC) method, respectively, which had become popular with displacement and deformation measurements in the field of experiment mechanics. Highlight 3: study on fracture behavior of concrete by optical image features. In the research, optical images were adopted to evaluate the failure behavior of concrete with different concrete mix proportion. Highlight 4: inhibition the appearance of concrete surface cracks and optimization the surface morphology of concrete by adding red mud. The experimental research presented that concrete by adding red mud and yellow phosphorus slag had fewer cracks and higher compression strength than concrete by only adding yellow phosphorus slag. We might conclude that a small amount of red mud could inhibit the appearance of concrete surface cracks and optimize the surface morphology of red mudyellow phosphorous slag-cement concrete. (Supplementary Materials)

\section{References}

[1] J.-S. Chen, B. Zhao, X.-M. Wang, Q.-L. Zhang, and L. Wang, "Cemented backfilling performance of yellow phosphorus slag," International Journal of Minerals, Metallurgy, and Materials, vol. 17, no. 1, pp. 121-126, 2010.

[2] J. Liu and D. Wang, "Application of ground granulate blast furnace slag-steel slag composite binder in a massive concrete structure under severe sulphate attack," Advances in Materials Science and Engineering, vol. 2017, Article ID 9493043, 9 pages, 2017.

[3] X. W. Liu, L. Yang, and B. Zhang, "Utilization of phosphorus slag and fly ash for the preparation of ready-mixed mortar," Applied Mechanics and Materials, vol. 423-426, pp. 987-992, 2013.

[4] G. H. Qi and X. Q. Peng, "Analysis on the pozzolanic effects of phosphorus slag powder in concrete," Key Engineering $\mathrm{Ma}$ terials, vol. 477, pp. 112-117, 2011.

[5] P. Krivenko, O. Kovalchuk, A. Pasko et al., "Development of alkali activated cements and concrete mixture design with high volumes of red mud," Construction and Building Materials, vol. 151, pp. 819-826, 2017.

[6] T. Kavas, "Use of boron waste as a fluxing agent in production of red mud brick," Building and Environment, vol. 41, no. 12, pp. 1779-1783, 2006.

[7] D. V. Ribeiro, J. A. Labrincha, and M. R. Morelli, "Effect of the addition of red mud on the corrosion parameters of reinforced concrete," Cement and Concrete Research, vol. 42, no. 1, pp. 124-133, 2012.

[8] D. Linora Metilda, C. Selvamony, R. Anandakumar, and A. Seeni, "Investigations on optimum possibility of replacing 
cement partially by redmud in concrete," Scientific Research and Essays, vol. 10, no. 4, pp. 137-143, 2015.

[9] S. Nenadovic, G. Mucsi, L. Kljajevic et al., "Physicochemical, mineralogical and radiological properties of red mud samples as secondary raw materials," Nuclear Technology and Radiation Protection, vol. 32, no. 3, pp. 261-266, 2017.

[10] X. Liu, N. Zhang, H. Sun, J. Zhang, and L. Li, "Structural investigation relating to the cementitious activity of bauxite residue-red mud," Cement and Concrete Research, vol. 41, no. 8, pp. 847-853, 2011.

[11] Z. Liu and H. Li, "Metallurgical process for valuable elements recovery from red mud-a review," Hydrometallurgy, vol. 155, pp. 29-43, 2015.

[12] M. Ma, G. Wang, Z. Yang, S. Huang, W. Guo, and Y. Shen, "Preparation, characterization, and photocatalytic properties of modified red mud," Advances in Materials Science and Engineering, vol. 2015, Article ID 907539, 6 pages, 2015.

[13] I. M. Nikbin, M. Aliaghazadeh, S. Charkhtab, and A. Fathollahpour, "Environmental impacts and mechanical properties of lightweight concrete containing bauxite residue (red mud)," Journal of Cleaner Production, vol. 172, pp. 2683-2694, 2018.

[14] A. Nabavi-Pelesaraei, R. Bayat, H. Hosseinzadeh-Bandbafha, H. Afrasyabi, and A. Berrada, "Prognostication of energy use and environmental impacts for recycle system of municipal solid waste management," Journal of Cleaner Production, vol. 154, pp. 602-613, 2017.

[15] J.-E. Kim, W.-S. Park, Y.-I. Jang et al., "Mechanical properties of energy efficient concretes made with binary, ternary, and quaternary cementitious blends of fly ash, blast furnace slag, and silica fume," International Journal of Concrete Structures and Materials, vol. 10, no. 3, pp. 97-108, 2016.

[16] H. Yazıc1, "The effect of curing conditions on compressive strength of ultra high strength concrete with high volume mineral admixtures," Building and Environment, vol. 42, no. 5, pp. 2083-2089, 2007.

[17] İ. Türkmen, R. Gül, and C. Çelik, “A Taguchi approach for investigation of some physical properties of concrete produced from mineral admixtures," Building and Environment, vol. 43, no. 6, pp. 1127-1137, 2008.

[18] J. Hu, "Comparison between the effects of superfine steel slag and superfine phosphorus slag on the long-term performances and durability of concrete," Journal of Thermal Analysis and Calorimetry, vol. 128, no. 3, pp. 1251-1263, 2017.

[19] S. W. Tang, X. H. Cai, Z. He, H. Y. Shao, Z. J. Li, and E. Chen, "Hydration process of fly ash blended cement pastes by impedance measurement," Construction and Building Materials, vol. 113, pp. 939-950, 2016.

[20] S. K. Rao, P. Sravana, and T. C. Rao, "Abrasion resistance and mechanical properties of roller compacted concrete with GGBS," Construction and Building Materials, vol. 114, pp. 925-933, 2016.

[21] N. Singh, "Fly ash-based geopolymer binder: a future construction material," Minerals, vol. 8, no. 7, p. 299, 2018.

[22] Y. Hefni, Y. A. E. Zaher, and M. A. Wahab, "Influence of activation of fly ash on the mechanical properties of concrete," Construction and Building Materials, vol. 172, pp. 728-734, 2018.

[23] Q. Wang, Z. Huang, and D. Wang, "Influence of high-volume electric furnace nickel slag and phosphorous slag on the properties of massive concrete," Journal of Thermal Analysis and Calorimetry, vol. 131, no. 2, pp. 873-885, 2018.

[24] C. Gong and N. Yang, "Effect of phosphate on the hydration of alkali-activated red mud-slag cementitious material,"
Cement and Concrete Research, vol. 30, no. 7, pp. 1013-1016, 2000.

[25] R. C. O. Romano, H. M. Bernardo, M. H. Maciel, R. G. Pileggi, and M. A. Cincotto, "Hydration of Portland cement with red mud as mineral addition," Journal of Thermal Analysis and Calorimetry, vol. 131, no. 3, pp. 2477-2490, 2018.

[26] Y. Zhou, H. Deng, and J. Liu, "Rational utilization of fine unclassified tailings and activated blast furnace slag with high calcium," Minerals, vol. 7, no. 4, p. 48, 2017.

[27] J.-M. Yang, D.-Y. Yoo, Y.-C. Kim, and Y.-S. Yoon, "Mechanical properties of steam cured high-strength steel fiberreinforced concrete with high-volume blast furnace slag," International Journal of Concrete Structures and Materials, vol. 11, no. 2, pp. 391-401, 2017.

[28] T. Tian, Y. Yan, Z. Hu, Y. Xu, Y. Chen, and J. Shi, "Utilization of original phosphogypsum for the preparation of foam concrete," Construction and Building Materials, vol. 115, pp. 143-152, 2016.

[29] S. Yoon, K. Mun, and W. Hyung, "Physical properties of activated slag concrete using phosphogypsum and waste lime as an activator," Journal of Asian Architecture and Building Engineering, vol. 14, no. 1, pp. 189-195, 2015.

[30] A. Allahverdi, S. Pilehvar, and M. Mahinroosta, "Influence of curing conditions on the mechanical and physical properties of chemically-activated phosphorous slag cement," Powder Technology, vol. 288, pp. 132-139, 2016.

[31] D. Li, J. Shen, L. Mao, and X. Wu, "The influence of admixtures on the properties of phosphorous slag cement," Cement and Concrete Research, vol. 30, no. 7, pp. 1169-1173, 2000.

[32] P. Gao, X. Lu, C. Yang, X. Li, N. Shi, and S. Jin, "Microstructure and pore structure of concrete mixed with superfine phosphorous slag and superplasticizer," Construction and Building Materials, vol. 22, no. 5, pp. 837-840, 2008.

[33] L. Guo-bin, S. Yi, D. Meng-meng, L. Hu ping, L. Kang-bi, and H. Liang, "Research progress on application technology of yellow phosphorus slag," in Proceedings of the 2013 International Conference on Biological, Medical and Chemical Engineering (BMCE 2013), pp. 517-521, Hong Kong, China, December 2013.

[34] W. C. Tang, Z. Wang, Y. Liu, and H. Z. Cui, "Influence of red mud on fresh and hardened properties of self-compacting concrete," Construction and Building Materials, vol. 178, pp. 288-300, 2018.

[35] M. R. Yogananda and K. S. Jagadish, "Pozzolanic properties of rice husk ash, burnt clay and red mud," Building and Environment, vol. 23, no. 4, pp. 303-308, 1988.

[36] J. Pera, R. Boumaza, and J. Ambroise, "Development of a pozzolanic pigment from red mud," Cement and Concrete Research, vol. 27, no. 10, pp. 1513-1522, 1997.

[37] M. Singh, S. N. Upadhayay, and P. M. Prasad, "Preparation of iron rich cements using red mud," Cement and Concrete Research, vol. 27, no. 7, pp. 1037-1046, 1997.

[38] K. Hyeok-Jung, S. Kang, and G. Choe, "Effect of red mud content on strength and efflorescence in pavement using alkali-activated slag cement," International Journal of Concrete Structures and Materials, vol. 12, no. 1, pp. 207-215, 2018.

[39] Z. Shen, Q. Zhang, W. Cheng, and Q. Chen, "Radioactivity of five typical general industrial solid wastes and its influence in solid waste recycling," Minerals, vol. 9, no. 3, p. 168, 2019.

[40] R.-X. Liu and C.-S. Poon, "Utilization of red mud derived from bauxite in self-compacting concrete," Journal of Cleaner Production, vol. 112, pp. 384-391, 2016. 
[41] Z. Pan, D. Li, J. Yu, and N. Yang, "Properties and microstructure of the hardened alkali-activated red mud-slag cementitious material," Cement and Concrete Research, vol. 33, no. 9, pp. 1437-1441, 2003.

[42] X. Jin, J. Tong, Y. Tian, and N. Jin, “Time-varying relative displacement field on the surface of concrete cover caused by reinforcement corrosion based on DIC measurement," Construction and Building Materials, vol. 159, pp. 695-703, 2018.

[43] V. Bonavetti, H. Donza, V. Rahhal, and E. Irassar, "Influence of initial curing on the properties of concrete containing limestone blended cement," Cement and Concrete Research, vol. 30, no. 5, pp. 703-708, 2000.

[44] Y. Q. Su, X. F. Yao, S. Wang, and Y. J. Ma, "Improvement on measurement accuracy of high-temperature DIC by grayscale-average technique," Optics and Lasers in Engineering, vol. 75, pp. 10-16, 2015.

[45] B. Pan, Z. Wang, and H. Xie, "Generalized spatial-gradientbased digital image correlation for displacement and shape measurement with subpixel accuracy," The Journal of Strain Analysis for Engineering Design, vol. 44, no. 8, pp. 659-669, 2009.

[46] X. Liu, Y. Ma, and X. Yao, "Experimental investigation of deformation and fracture in multilayered graded material," The Journal of Strain Analysis for Engineering Design, vol. 48, no. 8, pp. 474-481, 2013.

[47] D. Ribeiro and J. Labrincha, "Use of red mud as addition for portland cement mortars," Materials Science and Engineering A, vol. 4, pp. 1-8, 2010.

[48] A. N. Alzaed, "Effect of iron filings in concrete compression and tensile strength," International Journal of Recent Development in Engineering and Technology, vol. 3, pp. 121-125, 2014.

[49] E. P. Manfroi, M. Cheriaf, and J. C. Rocha, "Microstructure, mineralogy and environmental evaluation of cementitious composites produced with red mud waste," Construction and Building Materials, vol. 67, pp. 29-36, 2014.

[50] P. E. Tsakiridis, S. Agatzini-Leonardou, and P. Oustadakis, "Red mud addition in the raw meal for the production of Portland cement clinker," Journal of Hazardous Materials, vol. 116, no. 1-2, pp. 103-110, 2004.

[51] Y. Pontikes, P. Nikolopoulos, and G. N. Angelopoulos, "Thermal behaviour of clay mixtures with bauxite residue for the production of heavy-clay ceramics," Journal of the European Ceramic Society, vol. 27, no. 2-3, pp. 1645-1649, 2007.

[52] H.-P. Liu, X.-F. Huang, L.-P. Ma, D.-L. Chen, Z.-B. Shang, and M. Jiang, "Effect of $\mathrm{Fe}_{2} \mathrm{O}_{3}$ on the crystallization behavior of glass-ceramics produced from naturally cooled yellow phosphorus furnace slag," International Journal of Minerals, Metallurgy, and Materials, vol. 24, no. 3, pp. 316-323, 2017.

[53] O. E. Lebedeva, A. E. Dubovichenko, O. I. Kotsubinskaya, and A. G. Sarmurzina, "Preparation of porous glasses from phosphorus slag," Journal of Non-crystalline Solids, vol. 277, no. 1, pp. 10-14, 2000.

[54] F. P. Glasser, "The role of alkalis in controlling phase development in calcium aluminosilicate binders," in Proceedings of the First International conference on Alkaline Cements and Concretes, pp. 485-492, Kiev, Ukraine, October 1994.

[55] A. Souto-Martinez, E. A. Delesky, K. E. O. Foster, and W. V. Srubar, "A mathematical model for predicting the carbon sequestration potential of ordinary portland cement (OPC) concrete," Construction and Building Materials, vol. 147, pp. 417-427, 2017. 


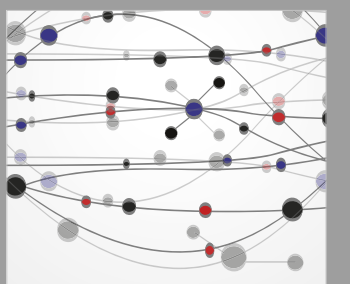

The Scientific World Journal
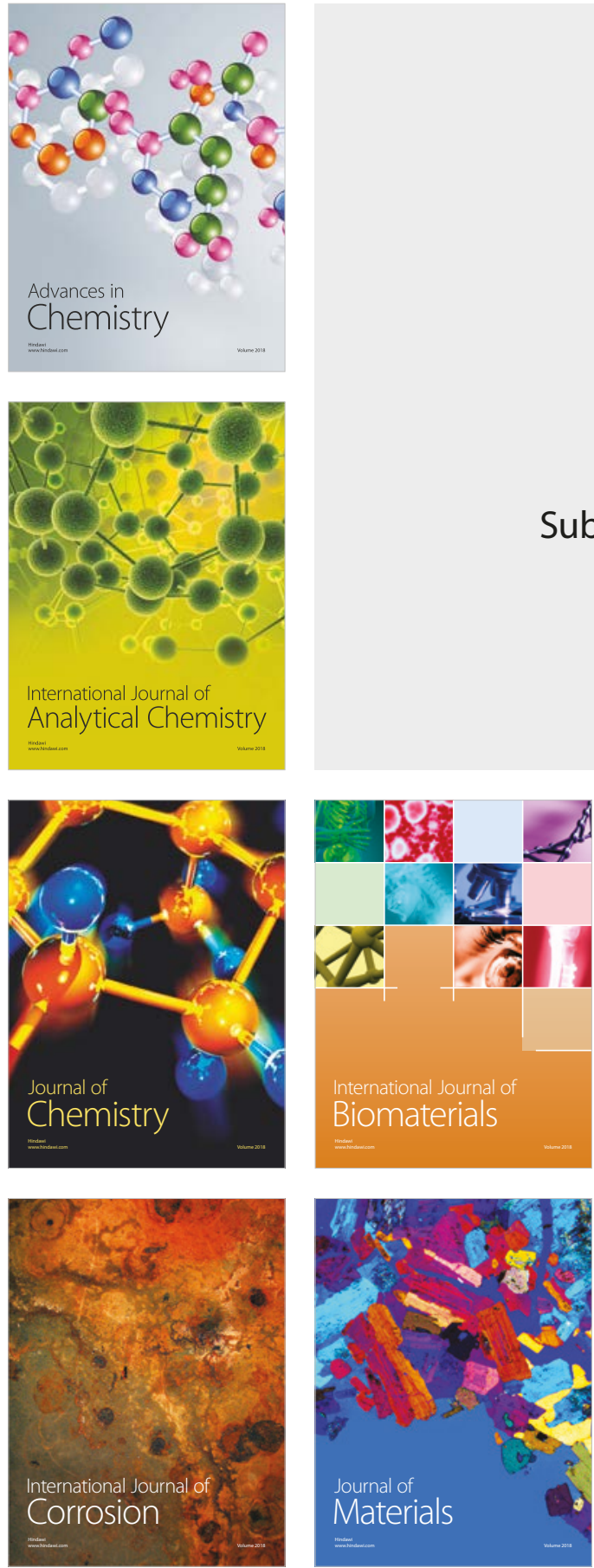

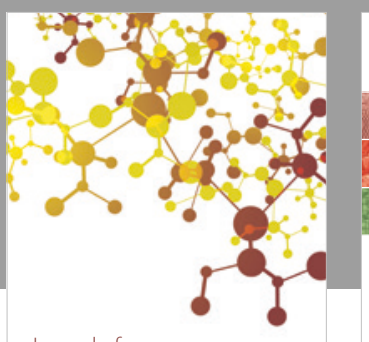

Journal of

Applied Chemistry
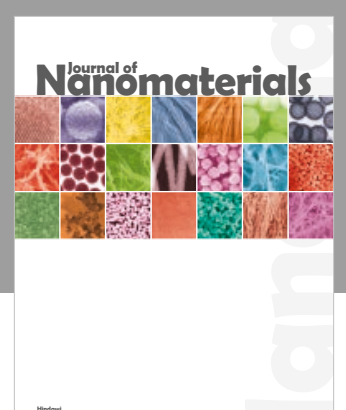

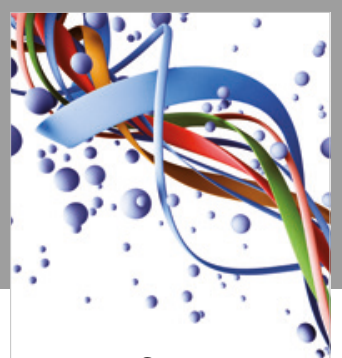

Scientifica

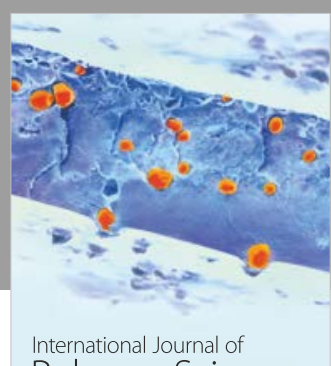

Polymer Science

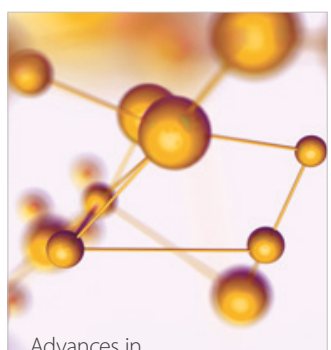

Physical Chemistry
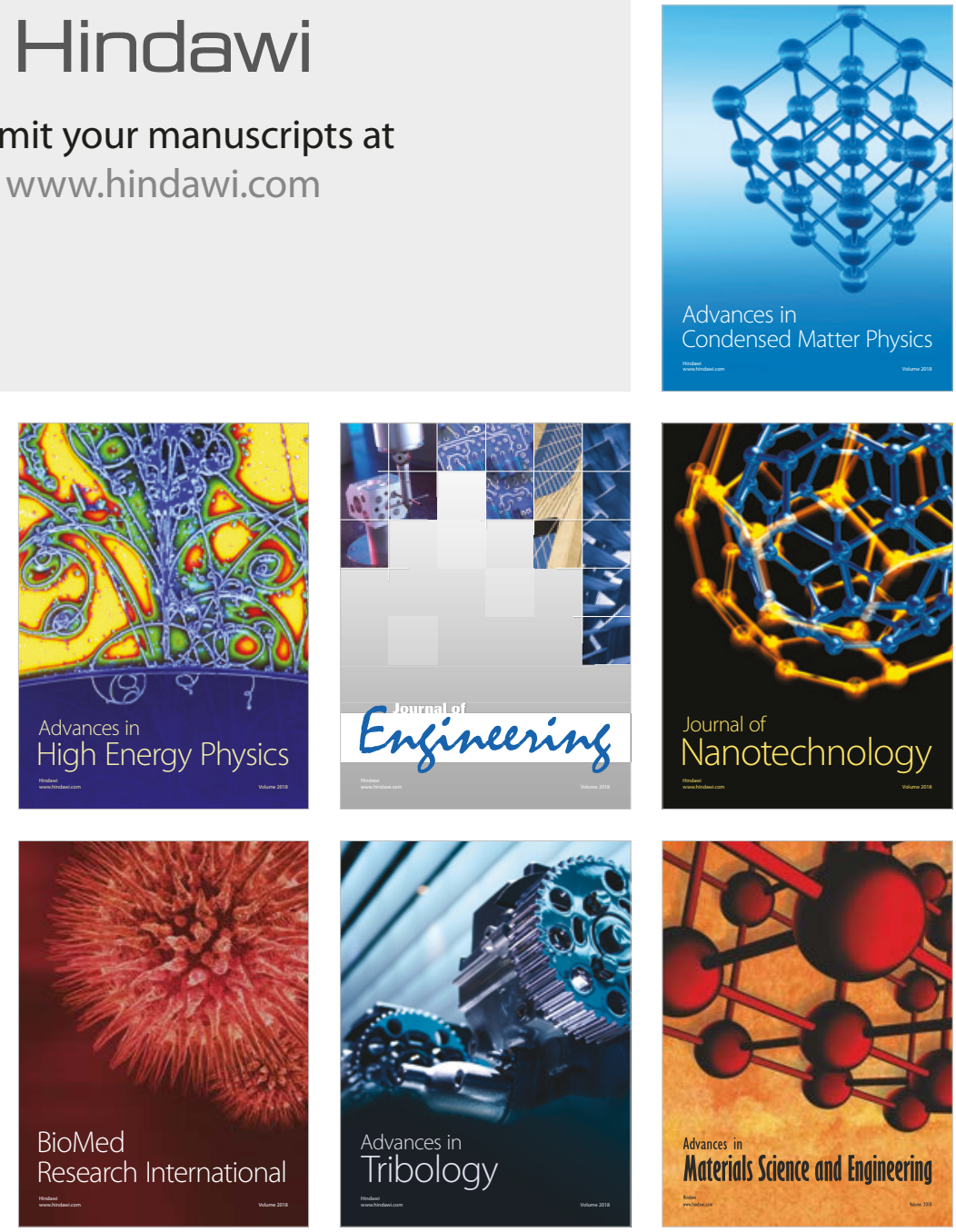